\title{
Türkiye'deki karaçam ağaçlandırma alanlarında besin stoklarının belirlenmesi
}

\author{
Determining the nutrient stocks in black pine plantation areas in Turkey
}

\author{
Dilek GÜNER ${ }^{1}$ \\ Kürşad ÖZKAN²
}

\begin{abstract}
${ }^{1}$ Orman Toprak ve Ekoloji Araştırmaları Enstitüsü Müdürlüğü, ESKİŞEHİR

${ }^{2}$ Isparta Uygulamalı Bilimler Üniversitesi, Orman Fakültesi, Orman Mühendisliğ Bölümü, ISPARTA
\end{abstract}

Sorumlu yazar (Corresponding author) Dilek GÜNER

dilekguner@ogm.gov.tr

Geliş tarihi (Received)

11.04.2019

Kabul Tarihi (Accepted)

14.06.2019
Atıf (To cite this article): Güner, D, Özkan, K (2019). Türkiye'deki karaçam ağaçlandırma alanlarında besin stoklarının belirlenmesi. Ormancılık Araştırma Dergisi, 6 (2), 192-207 DOI: https://doi.org/10.17568/ogmoad.552340

\section{Öz}

$\mathrm{Bu}$ çalışma, karaçam ağaçlandırma alanlarındaki besin stoklarını belirlemek amacıyla yapılmıştır. Örneklemeler verim sınıfı, gelişim çağ1 ve kapalılık bakımından farklılık gösteren toplam 46 alanda yapılmıştır. Laboratuvarda, araziden alınan toprak, ölü örtü, diri örtü ve ağaç bileşenlerine ait örneklerde $\mathrm{N}, \mathrm{P}, \mathrm{K}, \mathrm{Ca}, \mathrm{Mg}, \mathrm{S}, \mathrm{Na}, \mathrm{Fe}, \mathrm{Zn}$, $\mathrm{Mn}$ ve $\mathrm{Cu}$ analizleri yapılmıştır. Ekosistemin farklı bileşenlerine ait besin yoğunluklarının $(\%, \mathrm{ppm})$ ve besin stoklarının $(\mathrm{kg} / \mathrm{ha})$ meşcere tiplerine göre değişimi varyans analizi ile değerlendirilmiştir. Ağaç bileşenlerine ait besin yoğunlukları, genel olarak meşcere yaşına bağ11 olarak azalmıştır. N, P, K, Mg, S, Zn ve Mn yoğunluğu ibrelerde, $\mathrm{Na}$ ve Fe yoğunluğu kuru dalda, Ca yoğunluğu ise kuru dal ve kabukta en yüksek düzeyde bulunmuştur. Makro besin elementleri ağaçlarda en fazla ibre ve kabukta depolanmaktadır. Karaçam ağaçlandırma alanlarında, S ve Fe dışındaki besin stoklarının en önemli kısmını toprak oluşturmaktadır. Kükürt stoğu c meşcerelerinde $\left(\mathrm{d}_{1,3 \mathrm{~m}}=20,0-35,9 \mathrm{~cm}\right)$ ağaçlarda $(58,9 \mathrm{~kg} / \mathrm{ha})$, Fe stoğu ise $\mathrm{b}\left(\mathrm{d}_{1,3 \mathrm{~m}}=8,0-19,9 \mathrm{~cm}\right)$ ve $\mathrm{c}$ meşcerelerinde ölü örtüde en yüksek düzeyde bulunmuştur. Fe stoğunun önemli bileşeni olması sebebiyle ölü örtünün korunmasına önem verilmelidir. Besin kaybını en az düzeye indirmek amacıyla ekonomik değeri olmayan ibre, kuru dal, kabuk ve kökün ormanda bırakılmasına azami özen gösterilmelidir.

Anahtar Kelimeler: Pinus nigra, ekosistem, besin maddesi, aralama

\section{Abstract}

This study was carried out to determine nutrient stocks in black pine plantations. Samplings were done in 46 plots differing in yield class, development stages and canopy closure. $\mathrm{N}, \mathrm{P}, \mathrm{K}, \mathrm{Ca}, \mathrm{Mg}, \mathrm{S}, \mathrm{Na}, \mathrm{Fe}$, $\mathrm{Zn}, \mathrm{Mn}$ and $\mathrm{Cu}$ analyses were performed in soil, forest floor, ground cover and tree component samples. Changes in nutrient concentrations $(\%, \mathrm{ppm})$ and stocks $(\mathrm{kg} / \mathrm{ha})$ data belonging to various ecosystem compartments were evaluated by using analysis of variance. Nutrient concentration in tree components decreased with stand age. The highest $\mathrm{N}, \mathrm{P}, \mathrm{K}, \mathrm{Mg}, \mathrm{S}, \mathrm{Zn}$ and $\mathrm{Mn}$ concentrations were found in needle. The highest $\mathrm{Na}$ and $\mathrm{Fe}$ concentrations were measaured in dead branch while dead wood and bark included the highest $\mathrm{Ca}$ concentration. It was concluded that macro nutrients were notably stored in needle and bark. Whereas a substantial part of total nutrient stock were found in soil, except for $\mathrm{S}$ and $\mathrm{Fe}$. S stock were found the highest in trees in development stage c $(\mathrm{dbh}=20.0-35.9 \mathrm{~cm}, 58,9 \mathrm{~kg} / \mathrm{ha})$ while Fe stock in forest floor in development stage $\mathrm{b}(\mathrm{dbh}=8.0-19.9 \mathrm{~cm})$ and $\mathrm{c}$. Forest floor should be retained in the forest because of the fact that it is a notable resourse of Fe stock. Special care should be paid to leave the needles, dead branches, barks and roots following the logging to prevent loss of nutrients as much as possible.

Keywords: Pinus nigra, ecosystem, nutrient, thinning 


\section{Giriş}

Türkiye'nin orman varlığı 22.342.935 hektar olup, bu alanın \%19'unu (4.244.921 ha) karaçam (Pinus nigra subsp. pallasina (Lamb.) Holmboe) oluşturmaktadır (OGM, 2015). Karaçam Türkiye'de 165 2150 metrelerde saf veya meşe, göknar, çam ve ardıç gibi cinslerle karışık olarak; Marmara, Karadeniz, Ege, Akdeniz, İç Anadolu Bölgeleri ile Yukarı Fırat Bölümü’nde bulunmaktadır (Kandemir ve Mataracı, 2018). Karaçam, stebe en çok sokulan türlerden olması, toprak istekleri bakımından kanaatkar olması, sıcak ve kurağa dayanıklı olduğu gibi kış soğuklarına da dayanıklı olması (Saatçioğlu, 1969) sebebiyle, ağaçlandırma çalışmalarında en çok kullanılan türlerden biri olmuştur.

Dolayısıyla karaçam ağaçlandırma alanlarında ekosistemin farklı bileşenlerinde (toprak, ölü örtü, diri örtü, ibre, dal, gövde kabuğu, kök ve gövde odunu) depolanan besin stoklarının belirlenmesi ve bu stokların orman ekosistemine yapılacak müdahalelerden ne oranda etkileneceğinin ortaya konulması önem arz etmektedir. Besin maddesi rezervlerindeki azalma, özellikle ikinci nesil ağaçlandırma çalışmalarının başarısını olumsuz yönde etkileyip, orman ekosistemini zayıflatabileceği gibi, uzun vadede toprak karbonu stoğunu da etkileyebilecektir.

Ormanlardan çeşitli uygulamalar sonucu ağacın odunu, kabuğu, dalı, kökü ve hatta ibresi çıkartılmakta, ölü örtü de toplanmaktadır. Söz konusu uygulamaların orman ekosistemindeki mevcut besin stoklarına olan etkilerinin belirlenmesi, sürdürülebilir orman yönetiminin sağlanması bakımından oldukça önemlidir.

Günümüzde, enerji temininde, fosil yakıtlar yerine yenilenebilir biyokütle (biyoenerji) kullan1mı tercih edilmekte olup, bu amaçla ormanlardan sıklıkla faydalanılmaktadır. Avrupa topluluğunda, özellikle de Kuzey-Baltık ülkelerinde ormanlardan elde edilen yakıtın kullanımı, sürekli artmaktadır (EFC, 2010). Ayrıca biyokütlenin yenilenebilir olmas1, enerji sağlama güvenliğini de arttırmakta ve ithal edilen fosil yakıtlara olan bağımlılığ 1 azalttığ 1 için tercih edilmektedir. Ormanlar, enerji üretimi için önemli miktarda biyokütle yakıtı sağlayabilen rezervlere sahiptir (Kairiūkštis ve Jaskelevičius, 2003). Ormanlardan biyoenerji amaçlı faydalanılması da orman ekosistemindeki besin stoklarını etkileyen uygulamalardır. Biyoenerji ve faydalanma amaçlı ormanlara yapılacak müdahaleler, ormanların devamlılığını tehlikeye atmamalıdır.

Farklı ülkelerdeki orman ekosistemlerinde besin stoklarının bütün bileşenleriyle (toprak altı ve toprak üstü bitkisel kütle, ölü örtü, toprak) araşt1rıldığı birçok çalışma bulunmasına rağmen, Türkiye'de söz konusu bileşenlerin tamamını içeren çalışma sayısı sınırlıdır. Türkiye'deki çalışmalar daha çok, lokal alanlarda ve belirli bileşenlere yöneliktir (Irmak ve Çepel, 1969; Kantarc1, 1979; Kantarc1,1980; Dündar, 1989; Sevgi ve ark., 2001; Güner, 2006; Çepel ve ark., 1988; Tecimen ve ark., 2001; Tolunay, 2003; Tolunay, 2011). Bununla birlikte Isparta Orman Bölge Müdürlüğü doğal k1zılçam ormanlarında gençlik, sıklık, aralama ve tensil çağındaki meşcerelerde kesim artıklarının meşcereden uzaklaştırılmasının bitki besin bütçesi üzerine olan etkilerinin belirlendiği bir çalışma da mevcuttur (Eker ve ark., 2013). Araştırmamız, Türkiye'deki karaçam ağaçlandırma alanlarını temsil edebilecek geniş bir coğrafik alanda yürütülmesi ve ekosistemin bütün bileşenlerindeki (toprak, ölü örtü, diri örtü ve ağaçlar) besin stoklarını ele alarak değerlendirmesi bakımından diğer çalışmalardan ayrilmaktadır.

$\mathrm{Bu}$ çalışma karaçam ağaçlandırma alanlarında, i) ağaç bileșenlerinin (ibre, kuru dal, canlı dal, gövde odunu, gövde kabuğu ve kök) besin yoğunlukları arasındaki farklılıkları, ii) meşcere tiplerine göre toprak, ölü örtü, diri örtü, ağaç ve birim alanda depolanan besin stokları arasındaki farklılıkları belirlemek amacıyla yapılmıştır. Ayrıca, bakım ve gençleştirme çalışmaları için besin kaybını en aza düzeye indirecek önerilerde bulunulmuştur.

\section{Materyal ve Yöntem}

\subsection{Materyal}

Araştırmanın materyalini, 46 adet örnek alandan alınan toprak, ölü örtü ve diri örtü örnekleri ile kesilen ağaçlardan elde edilen ibre, kuru dal, canlı dal, gövde odunu, gövde kabuğu ve kök örnekleri oluşturmaktadır.

\subsubsection{Araştırma alanının tanıtımı}

Araştırma alanı Eskişehir, Afyonkarahisar, Kütahya, Kastamonu, Balıkesir ve Çanakkale il sınırları

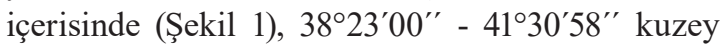
enlemleri ile $29^{\circ} 33^{\prime} 33^{\prime \prime}$ - 30 $03^{\prime} 37^{\prime \prime}$ doğu boylamları arasında bulunmaktadır. Türkiye'nin orman yetişme ortamı bölgelerinden 1-İç Anadolu Bölgesi, Batı İç Anadolu Yetişme Ortamı Bölgesi, 2- Marmara Bölgesi, Anadolu Bölümü, 3- Karadeniz Bölgesi, Batı Karadeniz Bölümü, 4- Ege Bölgesi, İç Ege Bölümü içerisinde kalmaktadır (Kantarc1, 2005).

1/500.000 ölçekli Türkiye Jeoloji Haritası'nın Ankara, İzmir ve Sinop paftaları içerisinde kalan araştırma alanında dasit, riyolit, bazalt, andezit, 


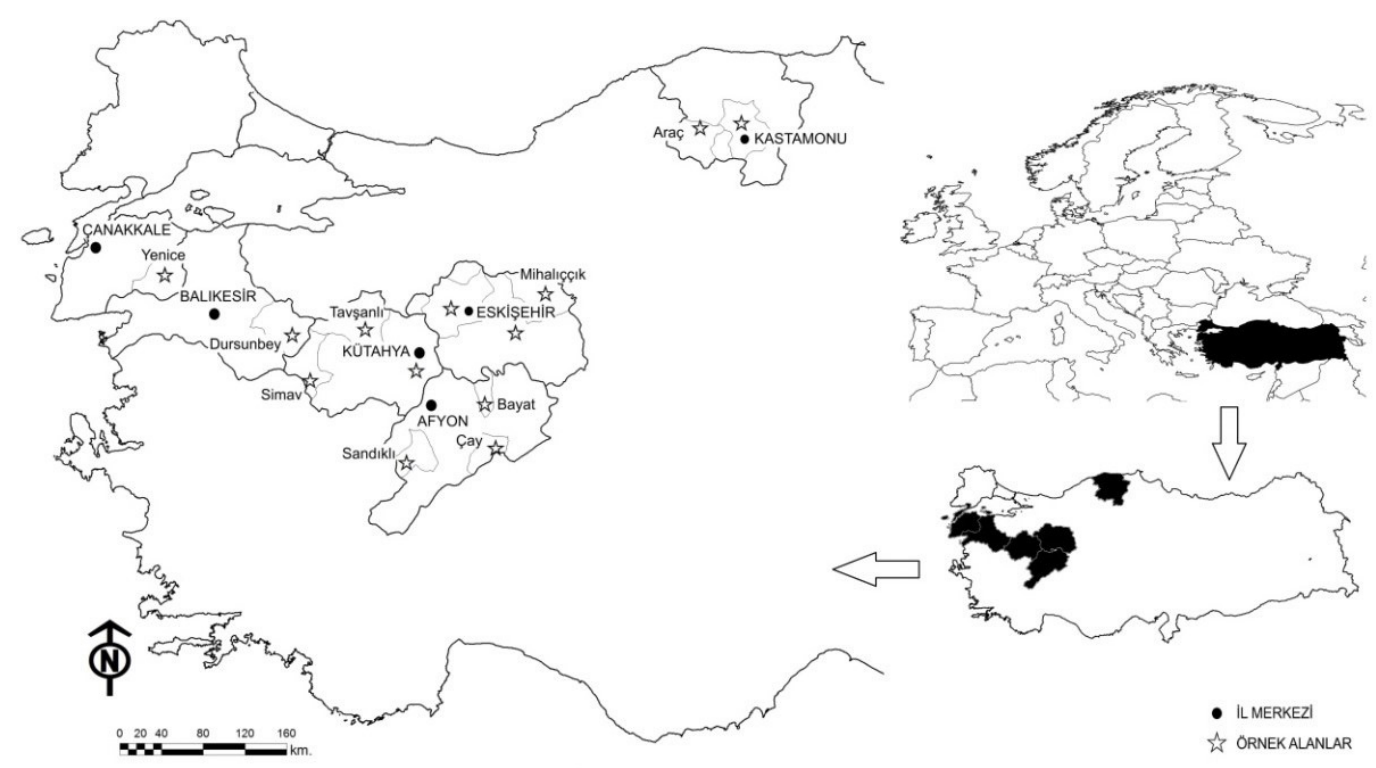

Şekil 1. Araştırma alanlarının konumu Figure 1. Location of the research area

granit, volkanik tüf, aglomera, breş, kuvarsit, mikaşist, kireç taşı ve serpantin anakayalar sıklıkla bulunmaktadır (Pamir ve Erentöz, 1975). En yaygin toprak tipi esmer orman toprağ 1 (Cambisols) ve solgun esmer orman toprağı (Luvisols)'dır (IUSS Working Group WRB, 2015).

İklim özelliklerinin değerlendirilmesinde ağaçlandırma alanlarına en yakın mesafede bulunan Kastamonu, Balıkesir, Dursunbey, Kütahya, Tavşanlı, Simav, Eskişehir, Mihalıççık, Sivrihisar, Emirdağı, Dinar ve Bolvadin meteoroloji istasyonu verileri kullanılmıştır. Meteoroloji istasyonu verileri araştırma alanına enterpole edilirken sicaklık değerleri her 100 m'de $0,5^{\circ} \mathrm{C}$ azaltılmış, yağış değeri ise her 100 m'de $54 \mathrm{~mm}$ arttırılmıştır (Özyuvacı, 1999). Meteoroloji istasyonu verilerine göre yıllık ortalama sıcaklık $8,9-14,5^{\circ} \mathrm{C}$, y1llık ortalama yüksek sicaklık 13,6-19,9 ${ }^{\circ} \mathrm{C}$, y1llık yağış ise 307,2-786,1 mm arasında değişmektedir. Araştırma alanında iklimin değişimi ve iklim tipleri yıllık ortalama yağış ve yıllık ortalama yüksek sıcaklık değerleri kullanılarak Erinç yöntemine göre incelenmiştir (Özyuvac1, 1999). Bu yönteme göre araştırma alanlarının iklimi yarı kurak ile çok nemli arasında değişmektedir.

\subsection{Yöntem}

Araştırma yöntemi; arazi, laboratuvar ve değerlendirme olmak üzere üç aşamada gerçekleştirilmiştir.

\subsubsection{Arazi çalışmaları}

Araştırmanın arazi aşaması, Orman Toprak ve
Ekoloji Araştırmaları Enstitüsü Müdürlüğü'nün "Karaçam ağaçlandırma alanlarında karbon stoklarının belirlenmesi [ESK-10(6303)]" isimli araştırma projesi kapsamında gerçekleştirilmiştir. $\mathrm{Bu}$ çalışmada ise ESK-10(6303) numaralı araştırma projesi kapsamında araziden alınan toprak, ölü örtü, çalı ve ot bileşenlerinin toprak altı ve toprak üstü kısımları ile ağaç bileșenlerinden ibre, kuru dal, canlı dal, gövde odunu, gövde kabuğu ve kök örnekleri üzerinde çalışılmıştır.

Arazi örneklemesinde aşağıda sıralanan yöntemler kullanılmıştır (Güner ve Çömez, 2014). Örneklemeler farklı yükselti, bakı, eğim ve yamaç konumu özelliklerine sahip, 6 meşcere tipinden (Çka, Çka3, Çkb2, Çkb3, Çkc2, Çkc3) ve her meşcere tipinden 7-8 adet olmak üzere, toplam 46 alandan yapılmıştır. Araştırma alanlarındaki meşcerelere ait bazı özellikler Tablo 1'de verilmiştir (Güner ve Çömez, 2014).

Örnek alanlar kare veya dikdörtgen şeklinde ve içerisine en az 15 adet fert girecek büyüklükte (10x10, 10x20 veya 20x20 m) alınmıştır. Her örnek alanın eğim, yükselti, bakı ve yamaç konumu özellikleri belirlenmiş, bir adet toprak çukuru açılmış, açılan toprak çukurundaki kesitte mineral toprak horizonları ayrılarak toprak tipi ve toprak özellikleri belirlenmiştir. Toprak ve yetişme ortamı arazide tanımlandıktan sonra, ayrilan toprak horizonlarından, hacim silindirleri ile bir litre hacminde toprak örnekleri alınmıştır.

Ölü örtü, örnek alanların 4 farklı kısmından ve $1 / 4 \mathrm{~m}^{2}$ $(50 \times 50 \mathrm{~cm})$ büyüklüğündeki alanlardan alınmıştır. 
Tablo 1. Araştırma alanlarındaki meșcere özellikleri

Table 1. Some stand characteristic in the research area

\begin{tabular}{lcccccc}
\hline \multirow{2}{*}{ Meşcere Özellikleri } & \multicolumn{7}{c}{ Meşcere Tipleri (Ort \pm SH) } \\
\cline { 2 - 6 } & Çka & Çka3 & Çkb2 & Çkb3 & Çkc2 & Çkc3 \\
\hline Örnek alan adedi & 7 & 8 & 8 & 8 & 7 & 8 \\
\hline Çap $\left(\mathrm{d}_{0}\right.$-cm) & $5,1 \pm 1,0$ & $9,3 \pm 0,9$ & - & - & - & - \\
Çap $\left(\mathrm{d}_{1,3}\right.$-cm) & - & $4,6 \pm 0,7$ & $15,7 \pm 1,4$ & $15,0 \pm 1,1$ & $26,4 \pm 1,2$ & $25,2 \pm 1,4$ \\
Boy (m) & $1,7 \pm 0,2$ & $2,9 \pm 0,2$ & $7,7 \pm 0,7$ & $8,8 \pm 0,7$ & $14,4 \pm 1,3$ & $13,8 \pm 0,9$ \\
Yaş & $9 \pm 1,2$ & $12 \pm 1,7$ & $37,3 \pm 2,4$ & $37 \pm 3,4$ & $47 \pm 3,8$ & $42 \pm 1,6$ \\
Kabuklu hacim (m³/ha) & - & $12,6 \pm 4,1$ & $130,1 \pm 23,0$ & $173,1 \pm 30,1$ & $239,3 \pm 35,9$ & $336,8 \pm 59,5$ \\
S1klık (adet/ha) & $1974 \pm 304$ & $3052 \pm 302$ & $1423 \pm 175$ & $1772 \pm 122$ & $613 \pm 103$ & $998 \pm 267$ \\
Göğüs yüzeyi $\left(\mathrm{m}^{2} / \mathrm{ha}\right)$ & - & $5,8 \pm 1,6$ & $27,7 \pm 3,6$ & $32,7 \pm 3,9$ & $33,0 \pm 4,3$ & $46,2 \pm 8,0$ \\
\hline
\end{tabular}

$\mathrm{d}_{0}=\operatorname{dip}$ çap $(\mathrm{cm}), \mathrm{d}_{1,3}=$ göğüs yüksekliğindeki çap $(\mathrm{cm})$, Ort: aritmetik ortalama, SH: standart hata, ha: hektar

Örnek alanlardaki diri örtünün çalı kısmı $4 \mathrm{~m}^{2}$ (2x2 m) alanda, otsu kısım ise $1 \mathrm{~m}^{2}(1 \times 1 \mathrm{~m})$ alanda kökleri ile birlikte sökülerek çıkartılmış ve kök boğazlarından kesilerek toprak üstü ve toprak altı kısımları ayrı ayrı tartılmıştır. Ayrıca diri örtünün örnek alanı kaplama oranı, hem çalı hem de ot için ayrı ayrı tahmin edilmiştir.

Örnek alanlarda tüm fertlerin çap ve boyları ölçülmüş, sağlıklı, tepesi ve dalları kırılmamış, baskı altında kalmamış bir fert kesilmiştir. Kesilen ağacın boyu, cm hassasiyetinde ölçülmüş, dip kütükte yıllık halkalardan yaş sayımı yapılmıştır. Daha sonra kesilen ağacın dalları temizlenip, gövde 2 m'lik bölümlere ayrılarak, ağırlıkları tartılmış ve nem içeriklerini belirlemek amaciyla her seksiyonun ortasından $5 \mathrm{~cm}$ kalınlığında diskler alınmıştır. İbre, dallardan ayrıldıktan sonra kümelenip; ibre, kuru dal ve canlı dal ağırlıkları ayrı ayrı tartılmıştır.

Örnek alanlardan kesilen her ferdin kökü kazma, balta, motorlu testere ve calaskar yardımıyla sökülerek; çapı $<1 \mathrm{~cm}, 1-4 \mathrm{~cm}$ ve $>4 \mathrm{~cm}$ olmak üzere üç gruba ayrılıp, taş ve topraklarından arınd1rıldıktan sonra tartılmıștır. Kökler nem ve besin içeriklerinin farklı olması sebebiyle çap gruplarına ayrılarak tartılmıştır (Ranger ve Gelhaye, 2001; Major ve ark., 2012).

Laboratuvarda fırın kurusu ağırlık ve besin içeriklerini belirlemek için kök (çapı $<1 \mathrm{~cm}, 1-4 \mathrm{~cm},>4$ $\mathrm{cm}$ ), gövde (5 cm kalınlığındaki diskler), dal (kuru ve canlı), ibre ve diri örtüden (çalı ve ot) alt örnekler alınarak arazide taze ağırlıkları belirlenmiştir.

\subsubsection{Laboratuvar çalışmaları}

Araziden alınan alt örnekler laboratuvarda etüvlere alınarak $65{ }^{\circ} \mathrm{C}$ 'de sabit ağırlığa kadar kurutulduktan sonra tartılıp, nem içerikleri belirlenmiş ve ağaç bileşenlerinin kuru ağırlıkları hesaplanmıştır. Kabuk miktarının hesaplanması için, gövdeden alınan disklerin kabuklu kuru ağırlığı tartıldık- tan sonra, kabuklar soyularak disklerin kabuksuz ağırlıkları tekrar tartılarak, aradaki farktan kabuk kuru ağırlığ 1 bulunmuştur. Kabuk ağırlığı/kabuklu disk ağırlığı oranından kabuk oranı hesaplanmıştır. Ölü örtü örneklerinin tamam $165{ }^{\circ} \mathrm{C}$ 'de sabit ağırlığa kadar kurutulduktan sonra tartılmış ve birim alandaki miktarı bulunmuştur. Daha sonra ögütülen bu örnekler analize hazırlanmıştır. Ancak odun, kabuk ve kök örneklerinde her ağaç için karma örnekler hazırlanarak analize alınmıştır. Karma örnekler, alındığı seksiyonun kuru kütlesinin, ağacın o bileşene ait toplam kuru kütlesine oranı dikkate alınarak hazırlanmıştır.

İbre, kuru dal, canlı dal, odun, kabuk, kök, çalı, ot ve ölü örtü örneklerinde, N Kjeldahl metoduna göre FOSS 8400 cihazında tayin edilmiştir (Foss Tecator, 2014). Nitrik-perklorik asit ile yaş yakılan bitki örneklerinde; $\mathrm{P}$ vanadamolibdofosforik sarı renk, S türbidimetrik yöntemle Shimadzu UV1800 spektrofotometre cihazında; $\mathrm{Na}$ ve K Jenway PFP 7 flame photometer cihazında; $\mathrm{Ca}, \mathrm{Mg}, \mathrm{Fe}, \mathrm{Cu}$, $\mathrm{Zn}$ ve $\mathrm{Mn}$ ise Shimadzu 6601-F atomic absorption spectrometer cihazında tayin edilmiştir (Kacar ve İnal, 2008).

Araziden alınan toprak örnekleri hava kurusu hale geldikten sonra ögütülüp 2 mm'lik elekten geçirilmiş ve tartılmıştır. Öğütülen ince toprakların bir kısmı $105^{\circ} \mathrm{C}$ 'de sabit ağırlığa kadar kurutulduktan sonra tartılıp, nem içerikleri belirlenmiştir. Geri kalan toprak örneklerinde toplam N Kjeldahl metoduna göre (Foss Tecator, 2014), alınabilir P asit reaksiyonlu topraklarda modifiye Bray ve Kurtz No.1 metoduna göre (TSE, 1990a), alkalen reaksiyonlu topraklarda Olsen ve ark. metoduna göre (TSE, 1990b), eksrakte edilebilir K (TSE, 1990c), değişebilir $\mathrm{Na}, \mathrm{Ca}, \mathrm{Mg}$, Fe ve $\mathrm{Mn}$ amonyum asetat metoduna göre, yarayışı $1 \mathrm{Cu}$ ve $\mathrm{Zn}$ çift asit $\left(\mathrm{HCl}+\mathrm{H}_{2} \mathrm{SO}_{4}\right)$ metoduna göre, eksrakte edilebilir $\mathrm{S}$ türbidimetrik metoda (Kacar, 1994) göre tayin edilmiştir. 


\subsubsection{Değerlendirme}

Ağaçlarda depolanan besin maddesi stoğu belirlenirken, analiz sonucu elde edilen \% (100 g kuru maddedeki miktar) veya ppm $(\mathrm{mg} / \mathrm{kg})$ besin elementleri miktarı, ESK-10(6303) numaralı araştırma projesi kapsamında tespit edilen örnek alanlardaki ağaç bileşenlerinin (ibre, kuru dal, canlı dal, odun, kabuk, kök) kuru kütlesi ile çarpılmak suretiyle hesaplanmıştır. Elde edilen değerler ile, hektara çevirme katsayısı kullanılarak bir hektar alandaki besin maddesi miktarı bulunmuştur. Yine ölü örtü ve diri örtünün örnek alanlardaki kuru kütlesi ile analiz sonucu bulunan besin yoğunlukları (\% veya ppm) çarpılarak örnek alandaki miktarı bulunmuş, daha sonra bu değerler, hektara dönüştürülmüştür. Besin elementlerinin topraktaki yoğunluğu (\% veya ppm) ait olduğu horizonun ince toprak miktar1 ile çarpılarak horizonlardaki besin elementi miktarı bulunmuş, horizonlardaki besin elementi miktarlarının toplanmasıyla da $1 \mathrm{~m}$ derinlik ve 1 $\mathrm{m}^{2}$ alandaki (pedon) besin elementi miktarı hesaplanmıştır. Bu değer de 10000 ile çarpılmak suretiyle örnek alanların hektardaki besin elementi değerleri elde edilmiştir. Ağaçlarda, diri örtüde, ölü örtüde ve toprakta depolanan besin elementi miktarları toplanarak, örnek alanların bir hektardaki toplam besin elementi stoğu bulunmuştur.

Meşcere tiplerine göre ekosistemde ve ekosistemin farklı bileşenlerinde depolanan besin elementi miktarları arasındaki farklılıklar varyans analizi ile incelenmiştir. Varyans analizlerinden önce veri setlerinin normal dağılım gösterip göstermediği Kolmogorov-Smirnov testi ile kontrol edilmiştir. Normal dağılım göstermeyen veri setlerine açısal dönüşüm $(\operatorname{ArcSin} \sqrt{x})$, karekök $(\sqrt{ } \mathrm{x})$ dönüşümü ve logaritma $(\log \mathrm{x})$ dönüşümü uygulanmıştır. Varyans analizi sonucunda istatistiksel bakımdan anlamlı $(\mathrm{p}<0,05)$ farklılıklar bulunması durumunda Duncan testi uygulanarak homojen (benzer) gruplar oluşturulmuştur. Sonuçlar $\alpha=0,05$ düzeyinde istatistiki olarak farklı kabul edilmiştir. İstatistik analizlerde SPSS paket programı kullanılmıştır (SPSS v.22.0®, 2015).

\section{Bulgular}

\subsection{Besin yoğunluklarına ait bulgular}

\subsubsection{Ağaç bileşenlerinin besin yoğunluklarına ait bulgular}

Ağaç bileşenlerine ait besin yoğunluklarının meşcere tiplerine göre değişimi Tablo 2'de verilmiştir. İbre ve gövde odunundaki N yoğunluğu bak1mından meşcere tipleri arasında önemli $(p<0,05)$ farklılıklar belirlenmiştir. İbredeki N yoğunluğu a meşcerelerinde en az, c meşcerelerinde ise en fazla bulunmuştur. Gövde odunundaki N yoğunluğu ise ibredeki $\mathrm{N}$ yoğunluğunun tersine a meşcerelerinde en yüksek, c meşcerelerinde ise en az düzeydedir. Kuru dal, canlı dal, kabuk ve kökteki azot yoğunluğu ise meşcere tipleri arasında önemli bir farklılık göstermemiştir ( $\mathrm{p}>0,05)$.

İbre, gövde odunu ve kabuktaki $\mathrm{P}$ yoğunluğu bakımından meşcere tipleri arasında istatistiksel bakımdan önemli $(p<0,05)$ farklılıklar bulunmuştur. İbrelerdeki P yoğunluğu a meşcerelerinden c meşcerelerine doğru artış gösterirken, gövde odunu ve kabuktaki P yoğunlukları a meşcerelerinden c meşcerelerine doğru azalış göstermiştir. Bir başka ifade ile meşcereler yaşlandıkça, ibrelerdeki P içeriği artarken, gövde odunu ve kabuktaki P içeriği azalmıştır.

Gövde odunu ve kabuktaki $\mathrm{K}$ yoğunluğu meşcere tiplerine göre anlamlı farkl1lıklar $(\mathrm{p}<0,05)$ göstermiş olup, a meşcerelerinde en yüksek seviyede bulunmuştur. İbre, kuru dal, canlı dal ve kök K yoğunluğu ise meşcere tipleri arasında anlamlı bir farklılık göstermemiştir ( $\mathrm{p}>0,05)$.

Kuru dal ve canlı dal Ca yoğunluğu, meşcere tiplerine göre önemli $(p<0,05)$ farklılıklar göstermiş, aynı gelişim çağında kapalılık arttıkça Ca yoğunluğu azalmıştır. İbre, gövde, kabuk ve kök Ca yogunlukları bakımından ise meşcere tipleri arasında önemli bir farklılık belirlenememiştir ( $p>0,05)$.

İbre ve kabuktaki $\mathrm{Mg}$ yoğunluğu, meşcere tiplerine göre önemli farklılıklar göstermiştir $(p<0,05)$. En yüksek ibre $\mathrm{Mg}$ yoğunluğu b meşcerelerinde, kabuk Mg yoğunluğu ise a meşcerelerinde bulunmuştur. Kuru dal, canlı dal, gövde ve kök Mg yoğunlukları ise meşcere tipleri arasında anlamlı bir farklılık göstermemiştir ( $\mathrm{p}>0,05)$.

Kabuk S yoğunluğu bakımından meşcere tipleri arasında istatistiksel bakımdan anlamlı bir farklılık bulunmuştur $(\mathrm{p}<0,05)$. Kabuktaki S yoğunluğu, a mescerelerinden c mescerelerine doğru azalmakta olup, c meşcerelerinde en düşük seviyeye ulaşmaktadır. Aynı gelişim çağlarında kapalılığın artmasına bağlı olarak kükürt yoğunluğu da artmıştır. Kabuk dışındaki ağaç bileşenlerinin S yoğunluklar1 ise meşcere tiplerine göre önemli bir farklılık göstermemiştir ( $\mathrm{p}>0,05)$.

Meşcere tipleri arasında kökteki $\mathrm{Fe}$ yoğunluğu bakımdan önemli bir farklılık $(\mathrm{p}<0,05)$ belirlenmiş olup, en fazla a meşcerelerinde bulunmuştur. Kabuktaki Zn yoğunluğu meşcere tiplerine göre önemli farklılıklar göstermiştir $(p<0,05)$. Zn yoğunluğu a meşcerelerinde en yüksek düzeyde bulunmuştur. İbre, kuru dal, canlı dal, gövde ve kök 
Tablo 2. Ağaç bileșenlerine ait besin yoğunluklarının meșcere tiplerine göre değișimi

Table 2. Change in nutrient concentrations of tree component according to stand types

\begin{tabular}{|c|c|c|c|c|c|c|c|c|c|}
\hline & \multirow{2}{*}{$\begin{array}{l}\text { Ağaç } \\
\text { Bileşenleri }\end{array}$} & \multicolumn{6}{|c|}{ Meşcere Tipleri $(\mathrm{Ort} \pm \mathrm{SH})$} & \multirow{2}{*}{$\begin{array}{c}\mathrm{F} \\
\text { Oran1 }\end{array}$} & \multirow{2}{*}{$\mathrm{p}$} \\
\hline & & Çka & Çka3 & Çkb2 & Çkb3 & Çkc2 & Çkc3 & & \\
\hline \multirow{6}{*}{$\begin{array}{l}\mathrm{N} \\
(\%)\end{array}$} & İbre & $0,90 \pm 0,06 \mathbf{a b}$ & $0,75 \pm 0,04 \mathbf{a}$ & $0,90 \pm 0,03 \mathbf{a b}$ & $0,95 \pm 0,05 \mathbf{b c}$ & $0,94 \pm 0,06 \mathbf{b c}$ & $1,09 \pm 0,05 \mathbf{c}$ & 4,437 & $<0,01$ \\
\hline & Kuru dal & & & $0,23 \pm 0,03 \mathbf{a}$ & $0,18 \pm 0,02 \mathbf{a}$ & $0,17 \pm 0,02 \mathbf{a}$ & $0,20 \pm 0,02 \mathbf{a}$ & 1,220 & $>0,05$ \\
\hline & Canlı dal & $0,29 \pm 0,02 \mathbf{a}$ & $0,21 \pm 0,01 \mathbf{a}$ & $0,29 \pm 0,05 \mathbf{a}$ & $0,22 \pm 0,02 \mathbf{a}$ & $0,20 \pm 0,01 \mathbf{a}$ & $0,24 \pm 0,02 \mathbf{a}$ & 1,849 & $>0,05$ \\
\hline & Gövde & $0,17 \pm 0,01 \mathbf{d}$ & $0,12 \pm 0,01 \mathbf{c}$ & $0,13 \pm 0,03 \mathbf{b c}$ & $0,09 \pm 0,003 \mathbf{a b}$ & $0,07 \pm 0,003 \mathbf{a}$ & $0,08 \pm 0,002 \mathbf{a}$ & 9,441 & $<0,001$ \\
\hline & Kabuk & $0,59 \pm 0,03 \mathbf{a}$ & $0,44 \pm 0,02 \mathbf{a}$ & $0,31 \pm 0,09 \mathbf{a}$ & $0,23 \pm 0,02 \mathbf{a}$ & $0,20 \pm 0,005 \mathbf{a}$ & $0,21 \pm 0,01 \mathbf{a}$ & 1,732 & $>0,05$ \\
\hline & Kök & $0,22 \pm 0,01 \mathbf{a}$ & $0,21 \pm 0,01 \mathbf{a}$ & $0,22 \pm 0,09 \mathbf{a}$ & $0,20 \pm 0,05 \mathbf{a}$ & $0,13 \pm 0,01 \mathbf{a}$ & $0,14 \pm 0,01 \mathbf{a}$ & 1,505 & $>0,05$ \\
\hline \multirow{6}{*}{$\begin{array}{c}\mathrm{P} \\
(\mathrm{ppm})\end{array}$} & İbre & $734 \pm 58 \mathbf{a}$ & $773 \pm 49 \mathbf{b}$ & $876 \pm 56 \mathbf{a b}$ & $839 \pm 34 \mathbf{a b}$ & $990 \pm 66 \mathbf{b c}$ & $1088 \pm 75$ c & 5,332 & $<0,01$ \\
\hline & Kuru dal & & & $113 \pm 19 \mathbf{a}$ & $75 \pm 9 \mathbf{a}$ & $112 \pm 19 \mathbf{a}$ & $95 \pm 4 \mathbf{a}$ & 1,596 & $>0,05$ \\
\hline & Canlı dal & $276 \pm 40 \mathbf{a}$ & $244 \pm 35 \mathbf{a}$ & $262 \pm 31 \mathbf{a}$ & $233 \pm 27 \mathbf{a}$ & $259 \pm 40 \mathbf{a}$ & $287 \pm 38 \mathbf{a}$ & 0,324 & $>0,05$ \\
\hline & Gövde & $146 \pm 32 c$ & $96 \pm 15 \mathbf{b c}$ & $52 \pm 3 \mathbf{a}$ & $52 \pm 7 \mathbf{a}$ & $69 \pm 5 \mathbf{a b}$ & $56 \pm 6 a$ & 5,370 & $<0,01$ \\
\hline & Kabuk & $580 \pm 36 \mathbf{b}$ & $461 \pm 34 \mathbf{b}$ & $183 \pm 15 \mathbf{a}$ & $177 \pm 13 \mathbf{a}$ & $174 \pm 29 \mathbf{a}$ & $173 \pm 16 \mathbf{a}$ & 36,958 & $<0,001$ \\
\hline & Kök & $253 \pm 20 \mathbf{a}$ & $265 \pm 43 \mathbf{a}$ & $192 \pm 18 \mathbf{a}$ & $209 \pm 18 \mathbf{a}$ & $296 \pm 48 \mathbf{a}$ & $329 \pm 42 \mathbf{a}$ & 2,318 & $>0,05$ \\
\hline \multirow{6}{*}{$\begin{array}{c}\mathrm{K} \\
(\mathrm{ppm})\end{array}$} & İbre & $4144 \pm 452 \mathbf{a}$ & $4314 \pm 301 \mathbf{a}$ & $4826 \pm 805 a$ & $4448 \pm 835 a$ & $5965 \pm 578 \mathbf{a}$ & $5718 \pm 721 \mathbf{a}$ & 1,312 & $>0,05$ \\
\hline & Kuru dal & & & $818 \pm 79 \mathbf{a}$ & $496 \pm 56 \mathbf{a}$ & $625 \pm 50 a$ & $744 \pm 160 \mathbf{a}$ & 2,050 & $>0,05$ \\
\hline & Canlı dal & $1646 \pm 186 \mathbf{a}$ & $1344 \pm 105 \mathbf{a}$ & $1958 \pm 224 \mathbf{a}$ & $1959 \pm 275 \mathbf{a}$ & $1755 \pm 215 \mathbf{a}$ & $2368 \pm 284 \mathbf{a}$ & 2,420 & $>0,05$ \\
\hline & Gövde & $1460 \pm 211 b$ & $1001 \pm 155 \mathbf{a}$ & $814 \pm 116 \mathbf{a}$ & $688 \pm 98 \mathbf{a}$ & $675 \pm 101 \mathbf{a}$ & $871 \pm 118 \mathbf{a}$ & 4,234 & $<0,01$ \\
\hline & Kabuk & $2574 \pm 305 \mathbf{b}$ & $2228 \pm 211 b$ & $1192 \pm 121 \mathbf{a}$ & $1288 \pm 178 \mathbf{a}$ & $1171 \pm 156 \mathbf{a}$ & $1283 \pm 251 \mathbf{a}$ & 8,220 & $<0,001$ \\
\hline & Kök & $1788 \pm 169 \mathbf{a}$ & $1725 \pm 139 \mathbf{a}$ & $1668 \pm 143 \mathbf{a}$ & $1856 \pm 245 a$ & $1837 \pm 206 \mathbf{a}$ & $2101 \pm 189 \mathbf{a}$ & 0,680 & $>0,05$ \\
\hline \multirow{6}{*}{$\begin{array}{c}\mathrm{Ca} \\
(\mathrm{ppm})\end{array}$} & İbre & $2783 \pm 263 \mathbf{a}$ & $4356 \pm 714 a$ & $3536 \pm 484 \mathbf{a}$ & $3545 \pm 374 a$ & $3007 \pm 516 \mathbf{a}$ & $2750 \pm 113 \mathbf{a}$ & 1,816 & $>0,05$ \\
\hline & Kuru dal & & & $6282 \pm 471 \mathbf{a b}$ & $5212 \pm 792 \mathbf{a}$ & $7271 \pm 598 \mathbf{b}$ & $5007 \pm 406 \mathbf{a}$ & 3,062 & $<0,05$ \\
\hline & Canlı dal & $3095 \pm 623 \mathbf{a}$ & $2915 \pm 351 \mathbf{a}$ & $4991 \pm 346 \mathbf{b}$ & $3916 \pm 372 \mathbf{a b}$ & $4820 \pm 784 \mathbf{b}$ & $4089 \pm 380 \mathbf{a b}$ & 3,098 & $<0,05$ \\
\hline & Gövde & $1190 \pm 132 \mathbf{a}$ & $1213 \pm 132 \mathbf{a}$ & $1453 \pm 141 \mathbf{a}$ & $1503 \pm 85 a$ & $1446 \pm 179 \mathbf{a}$ & $1385 \pm 148 \mathbf{a}$ & 0,904 & $>0,05$ \\
\hline & Kabuk & $3775 \pm 368 \mathbf{a}$ & $4516 \pm 766 a$ & $5783 \pm 865 \mathbf{a}$ & $5507 \pm 480 \mathbf{a}$ & $4924 \pm 736 \mathbf{a}$ & $4913 \pm 514 a$ & 1,173 & $>0,05$ \\
\hline & Kök & $1453 \pm 187 \mathbf{a}$ & $1506 \pm 167 \mathbf{a}$ & $1653 \pm 189 \mathbf{a}$ & $1531 \pm 159 \mathbf{a}$ & $1730 \pm 268 \mathbf{a}$ & $1688 \pm 265 \mathbf{a}$ & 0,265 & $>0,05$ \\
\hline \multirow{6}{*}{$\underset{(\mathrm{ppm})}{\mathrm{Mg}}$} & İbre & $1100 \pm 99 \mathbf{a}$ & $1071 \pm 98 \mathbf{a}$ & $1360 \pm 118 \mathbf{a b}$ & $1579 \pm 193 \mathbf{b}$ & $996 \pm 67 \mathbf{a}$ & $1157 \pm 132 \mathbf{a}$ & 2,956 & $<0,05$ \\
\hline & Kuru dal & & & $661 \pm 55 a$ & $588 \pm 93 \mathbf{a}$ & $539 \pm 63 \mathbf{a}$ & $537 \pm 56 \mathbf{a}$ & 0,708 & $>0,05$ \\
\hline & Canlı dal & $636 \pm 49 a$ & $437 \pm 69 \mathbf{a}$ & $378 \pm 119 \mathbf{a}$ & $671 \pm 82 \mathbf{a}$ & $599 \pm 55 \mathbf{a}$ & $668 \pm 43 a$ & 1,511 & $>0,05$ \\
\hline & Gövde & $461 \pm 43 \mathbf{a}$ & $296 \pm 44 a$ & $370 \pm 52 \mathbf{a}$ & $375 \pm 68 \mathbf{a}$ & $336 \pm 55 a$ & $376 \pm 34 \mathbf{a}$ & 1,100 & $>0,05$ \\
\hline & Kabuk & $1053 \pm 43 c$ & $848 \pm 110 b$ & $411 \pm 31 \mathbf{a}$ & $499 \pm 34 \mathbf{a}$ & $413 \pm 47 \mathbf{a}$ & $420 \pm 45 a$ & 20,399 & $<0,001$ \\
\hline & Kök & $525 \pm 67 \mathbf{a}$ & $360 \pm 47 \mathbf{a}$ & $531 \pm 85 a$ & $518 \pm 116 \mathbf{a}$ & $506 \pm 76 \mathbf{a}$ & $423 \pm 30 \mathbf{a}$ & 0,858 & $>0,05$ \\
\hline \multirow{6}{*}{$\begin{array}{c}\mathrm{S} \\
(\mathrm{ppm})\end{array}$} & İbre & $898 \pm 26 \mathbf{a}$ & $841 \pm 58 \mathbf{a}$ & $894 \pm 75 a$ & $989 \pm 84 \mathbf{a}$ & $1093 \pm 106 \mathbf{a}$ & $1074 \pm 49 \mathbf{a}$ & 2,115 & $>0,05$ \\
\hline & Kuru dal & & & $451 \pm 90 \mathbf{a}$ & $472 \pm 89 \mathbf{a}$ & $381 \pm 71 \mathbf{a}$ & $444 \pm 106 \mathbf{a}$ & 0,171 & $>0,05$ \\
\hline & Canlı dal & $357 \pm 43 \mathbf{a}$ & $366 \pm 49 \mathbf{a}$ & $387 \pm 40 \mathbf{a}$ & $250 \pm 60 \mathbf{a}$ & $313 \pm 95 \mathbf{a}$ & $315 \pm 62 \mathbf{a}$ & 0,682 & $>0,05$ \\
\hline & Gövde & $234 \pm 45 a$ & $250 \pm 39 a$ & $129 \pm 54 \mathbf{a}$ & $124 \pm 36 \mathbf{a}$ & $156 \pm 64 a$ & $97 \pm 41 \mathbf{a}$ & 1,757 & $>0,05$ \\
\hline & Kabuk & $569 \pm 80 \mathbf{b}$ & $592 \pm 57 \mathbf{b}$ & $408 \pm 58 \mathbf{a b}$ & $454 \pm 53 \mathbf{a b}$ & $302 \pm 57 \mathbf{a}$ & $336 \pm 51 \mathbf{a}$ & 3,855 & $<0,01$ \\
\hline & Kök & $480 \pm 84 \mathbf{a}$ & $598 \pm 72 \mathbf{a}$ & $440 \pm 54 \mathbf{a}$ & $451 \pm 45 \mathbf{a}$ & $465 \pm 92 \mathbf{a}$ & $411 \pm 66 \mathbf{a}$ & 2,318 & $>0,05$ \\
\hline & İbre & $65 \pm 8 \mathbf{a}$ & $76 \pm 10 a$ & $81 \pm 8 \mathbf{a}$ & $76 \pm 8 \mathbf{a}$ & $55 \pm 2 \mathbf{a}$ & $79 \pm 14 a$ & 1,356 & $>0,05$ \\
\hline & Kuru dal & & & $84 \pm 5 \mathbf{a}$ & $84 \pm 6 a$ & $70 \pm 5 \mathbf{a}$ & $92 \pm 13 \mathbf{a}$ & 1,051 & $>0,05$ \\
\hline & Canlı dal & $56 \pm 4 \mathbf{a}$ & $69 \pm 17 \mathbf{a}$ & $63 \pm 5 a$ & $67 \pm 5 a$ & $57 \pm 2 \mathbf{a}$ & $73 \pm 11 \mathbf{a}$ & 0,463 & $>0,05$ \\
\hline (ppm) & Gövde & $49 \pm 2 \mathbf{a}$ & $50 \pm 3 \mathbf{a}$ & $55 \pm 5 a$ & $61 \pm 6 \mathbf{a}$ & $50 \pm 4 a$ & $62 \pm 7 a$ & 1,022 & $>0,05$ \\
\hline & Kabuk & $75 \pm 4 \mathbf{a}$ & $72 \pm 10 \mathbf{a}$ & $69 \pm 5 a$ & $84 \pm 6 \mathbf{a}$ & $61 \pm 4 \mathbf{a}$ & $65 \pm 4 a$ & 1,732 & $>0,05$ \\
\hline & Kök & $87 \pm 12 \mathbf{a}$ & $66 \pm 7 a$ & $71 \pm 8 \mathbf{a}$ & $76 \pm 7 \mathbf{a}$ & $63 \pm 7 \mathbf{a}$ & $67 \pm 4 a$ & 1,047 & $>0,05$ \\
\hline & İbre & $122 \pm 7 \mathbf{a}$ & $137 \pm 13 \mathbf{a}$ & $147 \pm 5 a$ & $143 \pm 8 \mathbf{a}$ & $134 \pm 7 \mathbf{a}$ & $147 \pm 9 \mathbf{a}$ & 1,083 & $>0,05$ \\
\hline & Kuru dal & & & $239 \pm 33 \mathbf{a}$ & $205 \pm 23 \mathbf{a}$ & $282 \pm 48 \mathbf{a}$ & $265 \pm 28 \mathbf{a}$ & 0,987 & $>0,05$ \\
\hline $\mathrm{Fe}$ & Canlı dal & $163 \pm 13 \mathbf{a}$ & $166 \pm 37 \mathbf{a}$ & $136 \pm 14 a$ & $133 \pm 19 \mathbf{a}$ & $138 \pm 10 \mathbf{a}$ & $168 \pm 20 \mathbf{a}$ & 0,598 & $>0,05$ \\
\hline (ppm) & Gövde & $107 \pm 21 \mathbf{a}$ & $79 \pm 17 \mathbf{a}$ & $49 \pm 9 \mathbf{a}$ & $76 \pm 21 \mathbf{a}$ & $110 \pm 27 \mathbf{a}$ & $68 \pm 10 \mathbf{a}$ & 1,515 & $>0,05$ \\
\hline & Kabuk & $221 \pm 23 \mathbf{a}$ & $163 \pm 18 \mathbf{a}$ & $147 \pm 19 \mathbf{a}$ & $173 \pm 35 \mathbf{a}$ & $136 \pm 15 a$ & $120 \pm 9 \mathbf{a}$ & 2,440 & $>0,05$ \\
\hline & Kök & $217 \pm 26 \mathbf{b}$ & $217 \pm 21 \mathbf{b}$ & $130 \pm 15 \mathbf{a}$ & $171 \pm 25 \mathbf{a b}$ & $147 \pm 24 \mathbf{a}$ & $119 \pm 17 \mathbf{a}$ & 3,740 & $<0,01$ \\
\hline & İbre & $31 \pm 4 \mathbf{a}$ & $44 \pm 5 a$ & $48 \pm 6 \mathbf{a}$ & $40 \pm 3 \mathbf{a}$ & $44 \pm 3 \mathbf{a}$ & $50 \pm 6 \mathbf{a}$ & 1,465 & $>0,05$ \\
\hline & Kuru dal & & & $40 \pm 5 a$ & $27 \pm 2 \mathbf{a}$ & $32 \pm 1 \mathbf{a}$ & $32 \pm 2 \mathbf{a}$ & 2,632 & $>0,05$ \\
\hline $\mathrm{Zn}$ & Canlı dal & $41 \pm 7 \mathbf{a}$ & $33 \pm 4 \mathbf{a}$ & $34 \pm 2 \mathbf{a}$ & $27 \pm 1 \mathbf{a}$ & $32 \pm 3 \mathbf{a}$ & $34 \pm 1 \mathbf{a}$ & 1,452 & $>0,05$ \\
\hline (ppm) & Gövde & $34 \pm 8 \mathbf{a}$ & $20 \pm 2 \mathbf{a}$ & $26 \pm 8 \mathbf{a}$ & $23 \pm 3 \mathbf{a}$ & $24 \pm 8 \mathbf{a}$ & $17 \pm 1 \mathbf{a}$ & 1,077 & $>0,05$ \\
\hline & Kabuk & $56 \pm 7 c$ & $38 \pm 2 \mathbf{b}$ & $28 \pm 2 \mathbf{a b}$ & $30 \pm 2 \mathbf{a b}$ & $31 \pm 5 \mathbf{a b}$ & $25 \pm 1 \mathbf{a}$ & 7,959 & $<0,001$ \\
\hline & Kök & $24 \pm 5 \mathbf{a}$ & $25 \pm 6 \mathbf{a}$ & $23 \pm 3 \mathbf{a}$ & $19 \pm 1 \mathbf{a}$ & $20 \pm 2 \mathbf{a}$ & $23 \pm 2 \mathbf{a}$ & 0,297 & $>0,05$ \\
\hline & Íbre & $89 \pm 20 \mathbf{a}$ & $224 \pm 79 \mathbf{a}$ & $171 \pm 46 \mathbf{a}$ & $123 \pm 26 \mathbf{a}$ & $172 \pm 32 \mathbf{a}$ & $112 \pm 40 \mathbf{a}$ & 1,144 & $>0,05$ \\
\hline & Kuru dal & & & $85 \pm 8 \mathbf{a}$ & $66 \pm 11 \mathbf{a}$ & $81 \pm 15 a$ & $48 \pm 10 \mathbf{a}$ & 2,096 & $>0,05$ \\
\hline $\mathrm{Mn}$ & Canlı dal & $37 \pm 5 \mathbf{a}$ & $70 \pm 15 \mathbf{a}$ & $72 \pm 16 \mathbf{a}$ & $59 \pm 9 \mathbf{a}$ & $76 \pm 13 \mathbf{a}$ & $56 \pm 17 \mathbf{a}$ & 1,062 & $>0,05$ \\
\hline (ppm) & Gövde & $34 \pm 4 \mathbf{a}$ & $42 \pm 6 \mathbf{a}$ & $42 \pm 6 a$ & $35 \pm 4 \mathbf{a}$ & $40 \pm 4 \mathbf{a}$ & $31 \pm 5 \mathbf{a}$ & 0,713 & $>0,05$ \\
\hline & Kabuk & $35 \pm 8 \mathbf{a}$ & $82 \pm 22 \mathbf{a}$ & $48 \pm 12 \mathbf{a}$ & $51 \pm 8 \mathbf{a}$ & $40 \pm 5 a$ & $32 \pm 4 a$ & 1,526 & $>0,05$ \\
\hline & Kök & $25 \pm 6 \mathbf{a}$ & $43 \pm 9 \mathbf{a}$ & $37 \pm 9 \mathbf{a}$ & $43 \pm 6 \mathbf{a}$ & $37 \pm 6 \mathbf{a}$ & $36 \pm 9 \mathbf{a}$ & 0,596 & $>0,05$ \\
\hline & İbre & $30 \pm 3 \mathbf{a}$ & $29 \pm 3 \mathbf{a}$ & $31 \pm 3 \mathbf{a}$ & $27 \pm 1 \mathbf{a}$ & $29 \pm 3 \mathbf{a}$ & $28 \pm 2 \mathbf{a}$ & 0,202 & $>0,05$ \\
\hline & Kuru dal & & & $29 \pm 2 \mathbf{a}$ & $26 \pm 1 \mathbf{a}$ & $29 \pm 3 \mathbf{a}$ & $27 \pm 2 \mathbf{a}$ & 0,358 & $>0,05$ \\
\hline & Canlı dal & $31 \pm 3 \mathbf{a}$ & $26 \pm 3 \mathbf{a}$ & $29 \pm 2 \mathbf{a}$ & $27 \pm 1 \mathbf{a}$ & $29 \pm 3 \mathbf{a}$ & $27 \pm 2 \mathbf{a}$ & 0,370 & $>0,05$ \\
\hline (ppm) & Gövde & $31 \pm 3 \mathbf{a}$ & $25 \pm 3 \mathbf{a}$ & $28 \pm 2 \mathbf{a}$ & $26 \pm 1 \mathbf{a}$ & $28 \pm 4 \mathbf{a}$ & $27 \pm 2 \mathbf{a}$ & 0,488 & $>0,05$ \\
\hline & Kabuk & $33 \pm 3 \mathbf{a}$ & $27 \pm 3 \mathbf{a}$ & $28 \pm 1 \mathbf{a}$ & $28 \pm 1 \mathbf{a}$ & $29 \pm 3 \mathbf{a}$ & $29 \pm 2 \mathbf{a}$ & 0,512 & $>0,05$ \\
\hline & Kök & $31 \pm 3 \mathbf{a}$ & $25 \pm 3 \mathbf{a}$ & $27 \pm 1 \mathbf{a}$ & $26 \pm 1 \mathbf{a}$ & $29 \pm 3 \mathbf{a}$ & $27 \pm 2 \mathbf{a}$ & 0,530 & $>0,05$ \\
\hline
\end{tabular}

Satırlardaki aynı harfler aralarında fark bulunmayan $(\mathrm{p}>0,05)$ benzer grupları göstermektedir, SH: standart hata, $p$ : önem düzeyi 
Zn yoğunlukları bakımından ise meşcere tipleri arasında önemli bir farklılık belirlenememiştir $(\mathrm{p}>0,05)$. Ağaç bileşenlerinin $\mathrm{Na}, \mathrm{Mn}$ ve $\mathrm{Cu}$ yogunlukları bakımından meşcere tipleri arasında istatistiksel bakımdan anlamlı bir farklılık bulunamamıştır ( $\mathrm{p}>0,05)$.

Genel olarak değerlendirildiğinde N, P, K, Mg, S, $\mathrm{Zn}$ ve Mn yoğunluğu ibrelerde, $\mathrm{Na}$ ve Fe yoğunluğu kuru dalda, Ca yoğunluğu ise kuru dal ve kabukta en yüksek düzeyde bulunmuştur. En düşük $\mathrm{N}, \mathrm{P}, \mathrm{Mg}, \mathrm{S}, \mathrm{Na}$ ve Fe yoğunluğu gövdede, K yoğunluğu kuru dalda, $\mathrm{Ca}, \mathrm{Zn}$ ve $\mathrm{Mn}$ yoğunluğu ise gövde ve kökte tespit edilmiştir.

\subsection{2. Çalı bileşenlerinin besin yoğunluklarına ait bulgular}

Çalı bileşenlerine ait besin yoğunluklarının çalı türlerine göre değişimi Tablo 3'de görülmektedir. Tablo 3 incelendiğinde, çalıların toprak üstü kütlesindeki $\mathrm{N}$ ve $\mathrm{Zn}$ yoğunluğu $\mathrm{p}<0,001, \mathrm{P}, \mathrm{K}$ ve $\mathrm{Ca}$ yoğunluğu $\mathrm{p}<0,01, \mathrm{Mg}, \mathrm{S}$ ve Fe yoğunluğu ise $\mathrm{p}<0,05$ önem düzeyinde çalı türleri arasında farkl11ıklar göstermiştir. Toprak üstü kütledeki Na, Mn ve $\mathrm{Cu}$ yoğunluğu bakımından çalı türleri arasında anlamlı bir farklılık belirlenememiştir $(\mathrm{p}>0,05)$. Toprak üstü kütledeki N, P, K, Mg, S ve $\mathrm{Zn}$ yoğunluğu laden türünde, $\mathrm{Fe}$ yoğunluğu ardıç ve laden türlerinde, Ca yoğunluğu ise ardıç ve meşe türlerinde en yüksek düzeyde bulunmuştur. Çalıların toprak altı kütlesindeki Mn yoğunluğu p<0,001, P,
$\mathrm{S}$ ve $\mathrm{Zn}$ yoğunluğu $\mathrm{p}<0,01, \mathrm{~N}$ ve $\mathrm{K}$ yoğunluğu ise $\mathrm{p}<0,05$ önem düzeyinde çalı türleri arasında farklılıklar göstermiştir. Toprak altı bitkisel kütledeki $\mathrm{Ca}, \mathrm{Mg}, \mathrm{Na}, \mathrm{Fe}$ ve $\mathrm{Cu}$ yoğunluğu bakımından ise çalı türleri arasında anlamlı bir farklılık belirlenememiştir $(p>0,05)$. Çalıların toprak altı kütlesindeki N, P, Zn ve Mn yoğunluğu laden türünde, $\mathrm{K}$ ve $S$ yoğunluğu meşe ve laden türlerinde en yüksek düzeyde bulunmuştur.

\subsubsection{Ot bileşenlerinin besin yoğunluklarına ait bulgular}

Ot bileşenlerine ait besin yoğunluklarının meşcere tiplerine göre değişimi Tablo 4'de verilmiştir. Ot türü ayrımına gidilmeden yapılan değerlendirme sonucunda, toprak üstü ve toprak altı kütledeki N, $\mathrm{P}, \mathrm{K}, \mathrm{Mg}, \mathrm{S}, \mathrm{Fe}, \mathrm{Zn}$ ve $\mathrm{Mn}$ yoğunlukları meşcere tipleri arasında önemli bir farklılık göstermemiştir ( $p>0,05)$. Toprak üstü kütledeki $\mathrm{Cu}$ yoğunluğu meşcere tiplerine göre, önemli düzeyde farklılık göstermiş olup ( $\mathrm{p}<0,05)$, en yüksek Çkc3 meşcerelerinde bulunmuştur. Toprak altı kütledeki $\mathrm{Ca}$ ve $\mathrm{Na}$ yoğunluğu $\mathrm{p}<0,05$ önem düzeyinde meşcere tipleri arasında farklılık göstermiş olup, en fazla $\mathrm{Ca}$ ve $\mathrm{Na}$ yoğunluğu Çkc3 meşcerelerinde bulunmuştur.

\subsection{4. Ölü örtünün besin yoğunluklarına ait bulgular}

Ölü örtüye ait besin yoğunluklarının meşcere tiplerine göre değişimi Tablo 5'da görülmektedir. Ölü

Tablo 3. Çalı bileşenlerine ait besin yoğunluklarının türlere göre değişimi

Table 3. Change in nutrient concentrations of shrub components according to species

\begin{tabular}{|c|c|c|c|c|c|c|}
\hline & \multirow{2}{*}{$\begin{array}{l}\text { Çalı } \\
\text { Bilesenleri }\end{array}$} & \multicolumn{3}{|c|}{ Çalı Türleri (Ort \pm SH) } & \multirow{2}{*}{ F Oran1 } & \multirow[b]{2}{*}{$\mathrm{p}$} \\
\hline & & Meşe & Ardiç & Laden & & \\
\hline \multirow{2}{*}{$\begin{array}{l}\mathrm{N} \\
(\%)\end{array}$} & Toprak üstü & $0,49 \pm 0,03 \mathbf{a}$ & $0,42 \pm 0,03 \mathbf{a}$ & $0,64 \pm 0,04 \mathbf{b}$ & 9,598 & $<0,001$ \\
\hline & Toprak altı & $0,43 \pm 0,04 \mathbf{a}$ & $0,27 \pm 0,03 \mathbf{a}$ & $0,51 \pm 0,07 \mathbf{b}$ & 4,811 & $<0,05$ \\
\hline \multirow{2}{*}{$\begin{array}{c}\mathrm{P} \\
(\mathrm{ppm})\end{array}$} & Toprak üstü & $467 \pm 36 \mathbf{a}$ & $466 \pm 29 \mathbf{a}$ & $902 \pm 117 \mathbf{b}$ & 8,457 & $<0,01$ \\
\hline & Toprak altı & $472 \pm 66 \mathbf{a b}$ & $324 \pm 27 \mathbf{a}$ & $620 \pm 85 \mathbf{b}$ & 5,582 & $<0,01$ \\
\hline \multirow{2}{*}{$\begin{array}{c}\mathrm{K} \\
(\mathrm{ppm})\end{array}$} & Toprak üstü & $2662 \pm 443 \mathbf{a}$ & $2629 \pm 219 a$ & $4490 \pm 428 \mathbf{b}$ & 8,535 & $<0,01$ \\
\hline & Toprak altı & $2976 \pm 446 b$ & $2021 \pm 191 \mathbf{a}$ & $3263 \pm 448 \mathbf{b}$ & 3,585 & $<0,05$ \\
\hline \multirow{2}{*}{$\begin{array}{c}\mathrm{Ca} \\
(\mathrm{ppm})\end{array}$} & Toprak üstü & $14548 \pm 2654 b$ & $18464 \pm 2219 b$ & $7380 \pm 900 \mathbf{a}$ & 8,539 & $<0,01$ \\
\hline & Toprak altı & $10889 \pm 1988 \mathbf{a}$ & $8987 \pm 746 \mathbf{a}$ & $7576 \pm 1538 \mathbf{a}$ & 1,254 & $>0,05$ \\
\hline \multirow{2}{*}{$\begin{array}{c}\mathrm{Mg} \\
(\mathrm{ppm})\end{array}$} & Toprak üstü & $1035 \pm 132 \mathbf{a b}$ & $861 \pm 104 a$ & $1214 \pm 72 \mathbf{b}$ & 3,155 & $<0,05$ \\
\hline & Toprak altı & $902 \pm 122 \mathbf{a}$ & $910 \pm 140 \mathbf{a}$ & $945 \pm 130 \mathbf{a}$ & 0,030 & $>0,05$ \\
\hline \multirow{2}{*}{$\begin{array}{c}\mathrm{S} \\
(\mathrm{ppm})\end{array}$} & Toprak üstü & $519 \pm 49 \mathbf{a}$ & $511 \pm 54 a$ & $740 \pm 66 \mathbf{b}$ & 5,129 & $<0,05$ \\
\hline & Toprak altı & $558 \pm 79$ b & $286 \pm 37 \mathbf{a}$ & $497 \pm 64 \mathbf{b}$ & 5,574 & $<0,01$ \\
\hline \multirow{2}{*}{$\begin{array}{c}\mathrm{Na} \\
(\mathrm{ppm})\end{array}$} & Toprak üstü & $87 \pm 8 \mathbf{a}$ & $87 \pm 6 \mathbf{a}$ & $128 \pm 19 \mathbf{a}$ & 2,498 & $>0,05$ \\
\hline & Toprak altı & $104 \pm 15 \mathbf{a}$ & $87 \pm 6 \mathbf{a}$ & $139 \pm 21 \mathbf{a}$ & 3,222 & $>0,05$ \\
\hline \multirow{2}{*}{$\begin{array}{c}\mathrm{Fe} \\
(\mathrm{ppm})\end{array}$} & Toprak üstü & $170 \pm 31 \mathbf{a}$ & $285 \pm 26 \mathbf{b}$ & $311 \pm 48 \mathbf{b}$ & 3,714 & $<0,05$ \\
\hline & Toprak altı & $442 \pm 68 \mathbf{a}$ & $516 \pm 60 \mathbf{a}$ & $509 \pm 57 \mathbf{a}$ & 0,401 & $>0,05$ \\
\hline \multirow{2}{*}{$\begin{array}{c}\mathrm{Zn} \\
(\mathrm{ppm})\end{array}$} & Toprak üstü & $30 \pm 7 \mathbf{a}$ & $20 \pm 1 \mathbf{a}$ & $51 \pm 5 \mathbf{b}$ & 14,270 & $<0,001$ \\
\hline & Toprak altı & $28 \pm 12 \mathbf{a}$ & $20 \pm 4 \mathbf{a}$ & $41 \pm 4 b$ & 8,624 & $<0,01$ \\
\hline \multirow{2}{*}{$\begin{array}{c}\mathrm{Mn} \\
(\mathrm{ppm})\end{array}$} & Toprak üstü & $98 \pm 24 \mathbf{a}$ & $75 \pm 9 a$ & $117 \pm 16 \mathbf{a}$ & 1,626 & $>0,05$ \\
\hline & Toprak alt1 & $48 \pm 10 \mathbf{a}$ & $47 \pm 6 \mathbf{a}$ & $105 \pm 11 \mathbf{b}$ & 11,638 & $<0,001$ \\
\hline \multirow{2}{*}{$\begin{array}{c}\mathrm{Cu} \\
(\mathrm{ppm})\end{array}$} & Toprak üstü & $31 \pm 1 \mathbf{a}$ & $29 \pm 1 \mathbf{a}$ & $35 \pm 2 \mathbf{a}$ & 1,756 & $>0,05$ \\
\hline & Toprak alt1 & $31 \pm 1 \mathbf{a}$ & $31 \pm 1 \mathbf{a}$ & $34 \pm 2 \mathbf{a}$ & 0,760 & $>0,05$ \\
\hline
\end{tabular}

Satırlardaki aynı harfler aralarında fark bulunmayan $(p>0,05)$ benzer grupları göstermektedir, SH: standart hata, $p$ : önem düzeyi 
Tablo 4. Ot bileșenlerine ait besin yoğunluklarının meşcere tiplerine göre değișimi

Table 4. Change in nutrient concentrations of herbaceous cover components according to stand types

\begin{tabular}{|c|c|c|c|c|c|c|c|c|c|}
\hline & \multirow{2}{*}{$\begin{array}{l}\text { Ot } \\
\text { Bileşenleri }\end{array}$} & \multicolumn{6}{|c|}{ Meșcere Tipleri (Ort \pm SH) } & \multirow{2}{*}{$\begin{array}{c}\mathrm{F} \\
\text { Oran1 }\end{array}$} & \multirow[b]{2}{*}{$\mathrm{p}$} \\
\hline & & Çka & Çka3 & Çkb2 & Çkb3 & Çkc2 & Çkc3 & & \\
\hline \multirow{2}{*}{$\begin{array}{c}\mathrm{N} \\
(\%)\end{array}$} & Toprak üstü & $1,13 \pm 0,14 \mathbf{a}$ & $1,17 \pm 0,13 \mathbf{a}$ & $1,63 \pm 0,21 \mathbf{a}$ & $1,16 \pm 0,21 \mathbf{a}$ & $1,55 \pm 0,39 \mathbf{a}$ & $1,25 \pm 0,15 \mathbf{a}$ & 1,041 & $>0,05$ \\
\hline & Toprak altı & $0,82 \pm 0,09 \mathrm{a}$ & $0,77 \pm 0,05 \mathrm{a}$ & $1,10 \pm 0,12 \mathbf{a}$ & $0,76 \pm 0,10 \mathbf{a}$ & $0,91 \pm 0,15 \mathbf{a}$ & $1,01 \pm 0,13 \mathbf{a}$ & 1,706 & $>0,05$ \\
\hline \multirow{2}{*}{$\begin{array}{c}\mathrm{P} \\
(\mathrm{ppm})\end{array}$} & Toprak üstü & $918 \pm 180 \mathbf{a}$ & $1306 \pm 294 a$ & $1784 \pm 277 \mathbf{a}$ & $1426 \pm 258 \mathbf{a}$ & $2257 \pm 772 \mathbf{a}$ & $1175 \pm 245 \mathbf{a}$ & 1,083 & $>0,05$ \\
\hline & Toprak alt1 & $572 \pm 103 \mathbf{a}$ & $715 \pm 78 \mathbf{a}$ & $790 \pm 89 \mathbf{a}$ & $812 \pm 127 \mathbf{a}$ & $917 \pm 104 \mathbf{a}$ & $763 \pm 72 \mathbf{a}$ & 1,117 & $>0,05$ \\
\hline \multirow{2}{*}{$\underset{(\mathrm{ppm})}{\mathrm{K}}$} & Topra & $6812 \pm 1270 \mathbf{a}$ & $9263 \pm 2185 \mathbf{a}$ & $9995 \pm 1609 \mathbf{a}$ & $8790 \pm 2756 a$ & $14157 \pm 4550 \mathbf{a}$ & $6340 \pm 1007 \mathbf{a}$ & 1,017 & $>0,05$ \\
\hline & Topral & $3863 \pm 840 \mathbf{a}$ & $4482 \pm 434 \mathbf{a}$ & $4430 \pm 914 \mathbf{a}$ & $5067 \pm 1317 \mathbf{a}$ & $4386 \pm 875 \mathbf{a}$ & $3482 \pm 406 \mathbf{a}$ & 0,314 & $>0,05$ \\
\hline \multirow{2}{*}{$\begin{array}{c}\mathrm{Ca} \\
(\mathrm{ppm})\end{array}$} & Toprak üstü & $11850 \pm 3556 a$ & $5943 \pm 1242 \mathbf{a}$ & $7065 \pm 1683 \mathbf{a}$ & $7016 \pm 1590 \mathbf{a}$ & $9881 \pm 2587 \mathbf{a}$ & $9781 \pm 3750 \mathbf{a}$ & 0,940 & $>0,05$ \\
\hline & Toprak altı & $10397 \pm 3022 \mathbf{a}$ & $11673 \pm 6122 \mathbf{a}$ & $15571 \pm 3118 \mathbf{a}$ & $17905 \pm 4767 \mathbf{a}$ & $6871 \pm 2255 \mathbf{a}$ & $34276 \pm 8946 \mathbf{b}$ & 2,659 & $<0,05$ \\
\hline \multirow{2}{*}{$\begin{array}{c}\mathrm{Mg} \\
(\mathrm{ppm})\end{array}$} & Toprak ü & $3260 \pm 507 \mathbf{a}$ & $1886 \pm 314 a$ & $2572 \pm 519 \mathbf{a}$ & $2654 \pm 535 \mathbf{a}$ & $2413 \pm 499 \mathbf{a}$ & $2694 \pm 1174 a$ & 0,697 & $>0,05$ \\
\hline & Toprak altı & $3675 \pm 696 \mathbf{a}$ & $2411 \pm 565 \mathrm{a}$ & $3839 \pm 797 \mathbf{a}$ & $3781 \pm 632 \mathbf{a}$ & $2599 \pm 678 \mathbf{a}$ & $3835 \pm 940 \mathbf{a}$ & 0,872 & $>0,05$ \\
\hline \multirow{2}{*}{$\begin{array}{c}\mathrm{S} \\
(\mathrm{ppm})\end{array}$} & Toprak üstü & $1369 \pm 167 \mathbf{a}$ & $1249 \pm 164 \mathbf{a}$ & $1483 \pm 291 \mathbf{a}$ & $1258 \pm 192 \mathbf{a}$ & $1424 \pm 294 \mathbf{a}$ & $1421 \pm 202 \mathbf{a}$ & 0,205 & $>0,05$ \\
\hline & Topra & $1304 \pm 177 \mathbf{a}$ & $1205 \pm 65 \mathbf{a}$ & $1402 \pm 141 \mathbf{a}$ & $1324 \pm 148 \mathbf{a}$ & $1179 \pm 263 \mathbf{a}$ & $1291 \pm 99 \mathbf{a}$ & 0,259 & $>0,05$ \\
\hline \multirow{2}{*}{$\begin{array}{c}\mathrm{Na} \\
(\mathrm{ppm})\end{array}$} & Toprak üs & $201 \pm 28 \mathbf{a}$ & $264 \pm 77 \mathbf{a}$ & $243 \pm 34 a$ & $216 \pm 25 a$ & $226 \pm 44 a$ & $272 \pm 26 \mathbf{a}$ & 0,352 & $>0,05$ \\
\hline & Toprak altı & $200 \pm 49 \mathbf{a}$ & $234 \pm 13 \mathbf{a}$ & $284 \pm 28 \mathbf{a b}$ & $323 \pm 33 \mathbf{a b}$ & $200 \pm 56 \mathbf{a}$ & $360 \pm 48 b$ & 2,700 & $<0,05$ \\
\hline \multirow{2}{*}{$\begin{array}{c}\mathrm{Fe} \\
(\mathrm{ppm})\end{array}$} & Toprak üstü & $3482 \pm 584 \mathbf{a}$ & $2116 \pm 243 a$ & $2369 \pm 473 \mathbf{a}$ & $2491 \pm 675 a$ & $2224 \pm 439 a$ & $2364 \pm 797 \mathbf{a}$ & 0,832 & $>0,05$ \\
\hline & Toprak altı & $5470 \pm 1098 \mathbf{a}$ & $3937 \pm 440 \mathbf{a}$ & $4896 \pm 442 \mathbf{a}$ & $4867 \pm 733 \mathbf{a}$ & $4727 \pm 1580 \mathbf{a}$ & $4996 \pm 1661 \mathbf{a}$ & 0,320 & $>0,05$ \\
\hline \multirow{2}{*}{$\begin{array}{c}\mathrm{Zn} \\
(\mathrm{ppm})\end{array}$} & Toprak üstü & $68 \pm 11 \mathrm{a}$ & $65 \pm 7 a$ & $79 \pm 3 a$ & $68 \pm 10 \mathbf{a}$ & $87 \pm 10 \mathbf{a}$ & $82 \pm 10 \mathbf{a}$ & 0,714 & $>0,05$ \\
\hline & Toprak alt1 & $73 \pm 16 \mathbf{a}$ & $82 \pm 6 \mathbf{a}$ & $75 \pm 10 \mathbf{a}$ & $62 \pm 7 \mathbf{a}$ & $82 \pm 17 \mathbf{a}$ & $74 \pm 11 \mathbf{a}$ & 0,453 & $>0,05$ \\
\hline \multirow{2}{*}{$\begin{array}{c}\mathrm{Mn} \\
(\mathrm{ppm})\end{array}$} & Toprak üstü & $231 \pm 84 a$ & $142 \pm 36 \mathbf{a}$ & $192 \pm 42 \mathbf{a}$ & $193 \pm 44 a$ & $149 \pm 21 \mathbf{a}$ & $165 \pm 49 a$ & 0,372 & $>0,05$ \\
\hline & Toprak alt1 & $323 \pm 98 \mathbf{a}$ & $314 \pm 67 \mathbf{a}$ & $365 \pm 84 \mathbf{a}$ & $338 \pm 52 \mathbf{a}$ & $286 \pm 46 \mathbf{a}$ & $265 \pm 54 \mathbf{a}$ & 0,179 & $>0,05$ \\
\hline \multirow{2}{*}{$\begin{array}{c}\mathrm{Cu} \\
(\mathrm{ppm})\end{array}$} & Toprak üstü & $23 \pm 1 \mathbf{a}$ & $20 \pm 1 \mathbf{a}$ & $19 \pm 0,4 \mathbf{a}$ & $17 \pm 0,9 \mathbf{a}$ & $22 \pm 1 \mathbf{a}$ & $30 \pm 4 \mathbf{b}$ & 5,986 & $<0,01$ \\
\hline & Toprak altı & $24 \pm 3 \mathbf{a}$ & $25 \pm 5 \mathbf{a}$ & $26 \pm 3 \mathbf{a}$ & $23 \pm 2 \mathbf{a}$ & $22 \pm 2 \mathbf{a}$ & $36 \pm 5 \mathbf{a}$ & 0,975 & $>0,05$ \\
\hline
\end{tabular}

Satırlardaki aynı harfler aralarında fark bulunmayan $(\mathrm{p}>0,05)$ benzer grupları göstermektedir, SH: standart hata, $\mathrm{p}$ : önem düzeyi

örtüye ait $\mathrm{K}, \mathrm{Ca}, \mathrm{Mg}, \mathrm{Na}, \mathrm{Zn}, \mathrm{Mn}$ ve $\mathrm{Cu}$ yoğunlukları bakımından meşcere tipleri arasında önemli bir fark bulunmamıştır ( $\mathrm{p}>0,05)$. Buna karşılık ölü örtüdeki $\mathrm{N}, \mathrm{P}, \mathrm{S}$ ve Fe yoğunluğu meşcere tipleri arasında önemli $(p<0,05)$ farklılık göstermiş ve en az Çka3 meşcerelerinde bulunmuştur.

\subsubsection{Toprak horizonlarının besin yoğunlukla- rına ait bulgular}

Besin yoğunluklarının horizonlara göre değişimi Tablo 6'de verilmiştir. Genel olarak değerlendirildiğinde, besin elementlerinden $\mathrm{N}, \mathrm{P}$, $\mathrm{K}, \mathrm{Mg}, \mathrm{S}, \mathrm{Zn}$ ve $\mathrm{Mn}$ yoğunluğu toprak derinliği- ne bağlı olarak azalırken, $\mathrm{Ca}, \mathrm{Na}$ ve Fe yoğunluğu artış göstermiştir. $\mathrm{Cu}$ yoğunluğu ise esmer orman

topraklarında (Cambisol) toprak derinliğine bağlı olarak azalış gösterirken, solgun esmer orman topraklarında (Luvisol) artış göstermiştir.

\subsection{Besin stoklarına ait bulgular}

\subsubsection{Ağaç bileşenlerinin besin stoklarına ait bulgular}

Ağaç bileşenlerine ait besin stoklarının meşcere tiplerine göre değişimi Tablo 7'de verilmiştir. Genel olarak ibre, kuru dal, canlı dal, gövde, kabuk ve

Tablo 5. Ölü örtü besin yoğunluklarının meşcere tiplerine göre değişimi

Table 5. Change in nutrient concentrations of forest floor according to stand types

\begin{tabular}{|c|c|c|c|c|c|c|c|}
\hline \multirow{2}{*}{$\begin{array}{l}\text { Besin } \\
\text { Elementleri }\end{array}$} & \multicolumn{5}{|c|}{ Meşcere Tipleri (Ort \pm SH) } & \multirow{2}{*}{$\begin{array}{c}\mathrm{F} \\
\text { Oranı } \\
\end{array}$} & \multirow[b]{2}{*}{$\mathrm{p}$} \\
\hline & Çka3 & Çkb2 & Çkb3 & Çkc2 & Çkc3 & & \\
\hline $\mathrm{N}(\%)$ & $0,59 \pm 0,03 \mathbf{a}$ & $0,80 \pm 0,03 \mathbf{b}$ & $0,82 \pm 0,03 \mathbf{b}$ & $0,73 \pm 0,04 \mathbf{b}$ & $0,72 \pm 0,06 \mathbf{b}$ & 4,277 & $<0,01$ \\
\hline $\mathrm{P}(\mathrm{ppm})$ & $344 \pm 40 \mathbf{a}$ & $563 \pm 28$ b & $506 \pm 29 \mathbf{b}$ & $548 \pm 40$ b & $600 \pm 14 \mathbf{b}$ & 10,239 & $<0,001$ \\
\hline $\mathrm{K}(\mathrm{ppm})$ & $1522 \pm 149 \mathbf{a}$ & $2320 \pm 423 \mathbf{a}$ & $1778 \pm 219 \mathbf{a}$ & $2429 \pm 458 \mathbf{a}$ & $2783 \pm 404 \mathbf{a}$ & 2,191 & $>0,05$ \\
\hline $\mathrm{Ca}(\mathrm{ppm})$ & $20790 \pm 3479 \mathbf{a}$ & $19528 \pm 3728 \mathbf{a}$ & $17788 \pm 2056 \mathbf{a}$ & $15890 \pm 1501$ a & $21559 \pm 3178 \mathbf{a}$ & 0,571 & $>0,05$ \\
\hline $\mathrm{Mg}(\mathrm{ppm})$ & $1486 \pm 292 \mathbf{a}$ & $2065 \pm 321 \mathbf{a}$ & $2297 \pm 353 \mathbf{a}$ & $1921 \pm 312 \mathbf{a}$ & $2738 \pm 373 \mathbf{a}$ & 1,963 & $>0,05$ \\
\hline $\mathrm{S}(\mathrm{ppm})$ & $1031 \pm 54 \mathbf{a}$ & $1368 \pm 92 \mathbf{b}$ & $1333 \pm 78 \mathbf{b}$ & $1377 \pm 107 \mathbf{b}$ & $1557 \pm 95 \mathbf{b}$ & 4,936 & $<0,01$ \\
\hline $\mathrm{Na}(\mathrm{ppm})$ & $156 \pm 16 \mathbf{a}$ & $250 \pm 56 \mathbf{a}$ & $226 \pm 32 \mathbf{a}$ & $179 \pm 23 \mathbf{a}$ & $209 \pm 36 \mathbf{a}$ & 1,082 & $>0,05$ \\
\hline $\mathrm{Fe}(\mathrm{ppm})$ & $2725 \pm 383 \mathbf{a}$ & $4491 \pm 653$ abc & $3751 \pm 409$ ab & $4746 \pm 840$ bc & $5865 \pm 770 \mathbf{c}$ & 3,543 & $<0,05$ \\
\hline $\mathrm{Zn}(\mathrm{ppm})$ & $73 \pm 10 \mathbf{a}$ & $73 \pm 7 \mathbf{a}$ & $61 \pm 2 \mathbf{a}$ & $68 \pm 4 \mathbf{a}$ & $68 \pm 4 \mathbf{a}$ & 0,546 & $>0,05$ \\
\hline Mn (ppm) & $425 \pm 89 \mathbf{a}$ & $374 \pm 76 \mathbf{a}$ & $292 \pm 46 \mathbf{a}$ & $363 \pm 39$ a & $346 \pm 52 \mathbf{a}$ & 0,562 & $>0,05$ \\
\hline $\mathrm{Cu}(\mathrm{ppm})$ & $34 \pm 1 \mathbf{a}$ & $38 \pm 2 \mathbf{a}$ & $36 \pm 1 \mathbf{a}$ & $37 \pm 1 \mathbf{a}$ & $38 \pm 1 \mathbf{a}$ & 1,502 & $>0,05$ \\
\hline
\end{tabular}


Tablo 6. Toprağa ait besin yoğunluklarının horizonlara göre değișimi

Table 6. Change in nutrient concentrations of soil according to horizons

\begin{tabular}{|c|c|c|c|c|c|}
\hline \multicolumn{6}{|c|}{ Esmer Orman Toprakları (Cambisols) } \\
\hline Toprak & \multicolumn{5}{|c|}{ Mineral Toprak Horizonları (Ort $\pm \mathrm{SH})$} \\
\hline Özellikleri & Ah & \multicolumn{2}{|c|}{$\mathrm{Bv}$} & $\mathrm{BC}$ & $\mathrm{Cv}$ \\
\hline $\mathrm{N}(\%)$ & $0,23 \pm 0,02$ & \multicolumn{2}{|c|}{$0,14 \pm 0,01$} & $0,08 \pm 0,008$ & $0,06 \pm 0,004$ \\
\hline $\mathrm{P}(\mathrm{ppm})$ & $13,3 \pm 2,6$ & \multicolumn{2}{|c|}{$8,3 \pm 1,2$} & $6,0 \pm 1,0$ & $4,7 \pm 0,5$ \\
\hline $\mathrm{K}(\mathrm{ppm})$ & $485 \pm 53$ & \multicolumn{2}{|c|}{$316 \pm 33$} & $222 \pm 29$ & $193 \pm 29$ \\
\hline $\mathrm{Ca}(\mathrm{ppm})$ & $3804 \pm 500$ & \multicolumn{2}{|c|}{$4216 \pm 452$} & $4346 \pm 458$ & $4197 \pm 467$ \\
\hline $\operatorname{Mg}(\mathrm{ppm})$ & $917 \pm 207$ & \multicolumn{2}{|c|}{$785 \pm 172$} & $761 \pm 180$ & $770 \pm 169$ \\
\hline $\mathrm{S}(\mathrm{ppm})$ & $11,7 \pm 2,0$ & \multicolumn{2}{|c|}{$7,4 \pm 0,8$} & $6,4 \pm 0,5$ & $7,0 \pm 0,8$ \\
\hline $\mathrm{Na}(\mathrm{ppm})$ & $17,3 \pm 3,5$ & \multicolumn{2}{|c|}{$19,7 \pm 1,6$} & $27,3 \pm 4,5$ & $67,7 \pm 24,2$ \\
\hline $\mathrm{Fe}(\mathrm{ppm})$ & $2,5 \pm 0,7$ & \multicolumn{2}{|c|}{$3,2 \pm 0,5$} & $3,2 \pm 0,5$ & $3,3 \pm 0,6$ \\
\hline $\mathrm{Zn}(\mathrm{ppm})$ & $1,9 \pm 0,7$ & \multicolumn{2}{|c|}{$1,2 \pm 0,2$} & $1,0 \pm 0,1$ & $1,0 \pm 1,1$ \\
\hline $\mathrm{Mn}(\mathrm{ppm})$ & $28,3 \pm 7,4$ & \multicolumn{2}{|c|}{$32,1 \pm 6,6$} & $19,3 \pm 5,1$ & $14,2 \pm 3,7$ \\
\hline $\mathrm{Cu}(\mathrm{ppm})$ & $1,4 \pm 0,2$ & \multicolumn{2}{|c|}{$1,4 \pm 0,1$} & $1,3 \pm 0,1$ & $1,3 \pm 0,2$ \\
\hline \multicolumn{6}{|c|}{ Solgun Esmer Orman Toprakları (Luvisols) } \\
\hline Toprak & \multicolumn{5}{|c|}{ Mineral Toprak Horizonları $(\mathrm{Ort} \pm \mathrm{SH})$} \\
\hline Özellikleri & $\mathrm{Ah}$ & Ael & Bst & $\mathrm{BC}$ & $\mathrm{CV}$ \\
\hline $\mathrm{N}(\%)$ & $0,26 \pm 0,02$ & $0,15 \pm 0,01$ & $0,11 \pm 0,01$ & $0,08 \pm 0,008$ & $0,07 \pm 0,005$ \\
\hline $\mathrm{P}(\mathrm{ppm})$ & $17,9 \pm 2,1$ & $11,9 \pm 2,0$ & $8,0 \pm 1,4$ & $6,4 \pm 1,0$ & $5,0 \pm 0,7$ \\
\hline $\mathrm{K}(\mathrm{ppm})$ & $237 \pm 35$ & $184 \pm 21$ & $166 \pm 19$ & $157 \pm 18$ & $134 \pm 15$ \\
\hline $\mathrm{Ca}(\mathrm{ppm})$ & $1707 \pm 340$ & $1526 \pm 215$ & $1488 \pm 235$ & $1671 \pm 273$ & $1808 \pm 307$ \\
\hline $\mathrm{Mg}(\mathrm{ppm})$ & $208 \pm 24$ & $220 \pm 18$ & $205 \pm 19$ & $216 \pm 20$ & $241 \pm 26$ \\
\hline $\mathrm{S}(\mathrm{ppm})$ & $12,3 \pm 2,0$ & $6,5 \pm 0,6$ & $5,0 \pm 0,4$ & $4,0 \pm 0,4$ & $5,1 \pm 0,8$ \\
\hline $\mathrm{Na}(\mathrm{ppm})$ & $14,8 \pm 1,4$ & $17,5 \pm 1,8$ & $18,2 \pm 1,5$ & $21,7 \pm 2,3$ & $47,0 \pm 23,1$ \\
\hline $\mathrm{Fe}(\mathrm{ppm})$ & $3,0 \pm 0,3$ & $3,2 \pm 0,3$ & $3,1 \pm 0,3$ & $3,1 \pm 0,3$ & $3,2 \pm 0,3$ \\
\hline $\mathrm{Zn}(\mathrm{ppm})$ & $5,1 \pm 0,8$ & $2,3 \pm 0,3$ & $1,7 \pm 0,2$ & $1,6 \pm 0,2$ & $1,3 \pm 0,1$ \\
\hline Mn (ppm) & $50,4 \pm 5,8$ & $50,8 \pm 5,1$ & $43,3 \pm 4,9$ & $33,4 \pm 4,6$ & $30,3 \pm 5,8$ \\
\hline $\mathrm{Cu}(\mathrm{ppm})$ & $1,5 \pm 0,1$ & $1,9 \pm 0,1$ & $2,0 \pm 0,1$ & $2,1 \pm 0,2$ & $2,1 \pm 0,2$ \\
\hline
\end{tabular}

Ort: aritmetik ortalama, SH: standart hata

kökteki N, P, K, Ca, Mg, S, Na, Fe, Zn, Mn ve $\mathrm{Cu}$ yoğunluğu meşcere tipleri arasında istatistiksel bakımdan önemli $(\mathrm{p}<0,05)$ farklılıklar göstermiştir. Sadece kuru daldaki $\mathrm{Mg}$, S ve Mn yoğunluğu ile ibredeki Mn yoğunluğu bakımından meşcere tipleri arasında anlamlı bir farklılık belirlenememiştir $(\mathrm{p}>0,05)$. Genel olarak değerlendirildiğinde, besin stokları Çka meşcerelerinden Çkc3 meşcerelerine doğru artmış ve en yüksek besin stokları Çkc3 meşcerelerinde bulunmuştur. Birim alandaki N, $\mathrm{P}$, $\mathrm{K}$ ve $\mathrm{S}$ stoğu ibrede, $\mathrm{Mg}, \mathrm{Na}, \mathrm{Fe}, \mathrm{Zn}$ ve $\mathrm{Cu}$ stoğu gövdede, Ca stoğu gövde, canlı dal ve kabukta, Mn stoğu ise gövde ve ibrede en fazla bulunmuştur.

\subsubsection{Ekosistemin farklı bileşenlerinin besin stoklarına ait bulgular}

Karaçam ağaçlandırma alanlarında ekosistemin farklı bileşenlerinde depolanan besin stoklarının meşcere tiplerine göre değişimi Tablo 8'da verilmiştir. Tablo 8 incelendiğinde, ağaçlarda depolanan $\mathrm{N}, \mathrm{P}, \mathrm{K}, \mathrm{Ca}, \mathrm{Mg}, \mathrm{S}, \mathrm{Na}, \mathrm{Fe}, \mathrm{Zn}$ ve $\mathrm{Cu}$ stoğu $\mathrm{p}<0,001$, Mn stoğu ise $\mathrm{p}<0,01$ önem düzeyinde meşcere tipleri arasında önemli farklılıklar göstermiştir. Ağaçlardaki tüm besin stokları, meşcere kapalılığının ve gelişim çağının artmasına bağlı olarak artış göstermiş ve en fazla besin stoğu Çkc3 meşcerelerinde tespit edilmiştir.

Çalılarda depolanan besin stokları bakımından meşcere tipleri arasında anlamlı bir farklılık bulunama- miştır ( $\mathrm{p}>0,05$ ). Otlarda depolanan $\mathrm{N}, \mathrm{P}, \mathrm{K}, \mathrm{Mg}, \mathrm{S}$, $\mathrm{Fe}, \mathrm{Mn}$ ve $\mathrm{Cu}$ stoğu $\mathrm{p}<0,01, \mathrm{Na}$ ve $\mathrm{Zn}$ stoğu $\mathrm{p}<0,05$ önem düzeyinde meşcere tipleri arasında anlamlı farklılıklar göstermiștir. Otlarda depolanan Ca stoğu bakımından ise meşcere tipleri arasında anlamlı bir farklılık belirlenememiştir $(\mathrm{p}>0,05)$. Otlarda depolanan $\mathrm{N}, \mathrm{P}, \mathrm{K}, \mathrm{Mg}, \mathrm{S}, \mathrm{Na}, \mathrm{Fe}, \mathrm{Zn}, \mathrm{Mn}$ ve $\mathrm{Cu}$ stoğu a meşcerelerinde yüksek, b ve c meşcerelerinde ise daha düşük düzeyde bulunmuştur.

Ölü örtüde depolanan N, P, K, Ca, Mg, S, Na, Fe, $\mathrm{Zn}, \mathrm{Mn}$ ve $\mathrm{Cu}$ stoğu bakımından meşcere tipleri arasında istatistiksel bakımdan anlamlı $(\mathrm{p}<0,001)$ farkl111klar bulunmuş olup, ölü örtüde depolanan besin stokları a meşcerelerinden c meşcerelerine doğru artmıştır.

Toprakta depolanan $\mathrm{Ca}$, Na ve Fe stoğu bakımından meşcere tipleri arasında anlamlı farklılıklar $(\mathrm{p}<0,05)$ belirlenirken, $\mathrm{N}, \mathrm{P}, \mathrm{K}, \mathrm{Mg}, \mathrm{S}, \mathrm{Zn}, \mathrm{Mn}$ ve $\mathrm{Cu}$ stoğu bakımından ise anlamlı farklılıklar bulunamamıştır $(\mathrm{p}>0,05)$. Toprakta depolanan $\mathrm{Ca}, \mathrm{Na}$ ve Fe stoğu Çka ve Çka3 meşcerelerinde en yüksek düzeydedir.

Ekosistemde depolanan $\mathrm{P}, \mathrm{Ca}, \mathrm{S}, \mathrm{Na}$ ve Fe stoğu bakımından meşcere tipleri arasındaki farklılıklar önemli $(\mathrm{p}<0,05)$; N, K, Mg, Zn, Mn ve $\mathrm{Cu}$ stoğu bakımından ise meşcere tipleri arasındaki farkl1lıklar önemsiz ( $\mathrm{p}>0,05)$ bulunmuştur. 
Tablo 7. Ağaç bileșenlerine ait besin stoklarının meșcere tiplerine göre değișimi (kg/ha)

Table 7. Change in nutrient stocks of tree components according to stand types ( $\mathrm{kg} / \mathrm{ha})$

\begin{tabular}{|c|c|c|c|c|c|c|c|c|c|}
\hline & \multirow{2}{*}{$\begin{array}{l}\text { Ağaç } \\
\text { Bileşenleri }\end{array}$} & \multicolumn{6}{|c|}{ Meşcere Tipleri (Ort $\pm \mathrm{SH})$} & \multirow{2}{*}{$\begin{array}{c}\mathrm{F} \\
\text { Oran1 }\end{array}$} & \multirow[b]{2}{*}{$\mathrm{p}$} \\
\hline & & Çka & Çka3 & Çkb2 & Çkb3 & Çkc2 & Çkc3 & & \\
\hline \multirow{6}{*}{$\mathrm{N}$} & İbre & $19,0 \pm 8,0 \mathbf{a}$ & $67,4 \pm 11,4 \mathbf{a b}$ & $86,2 \pm 11,1 \mathbf{b}$ & $106,1 \pm 15,2 \mathbf{b}$ & $117,7 \pm 18,4 \mathbf{b}$ & $185,5 \pm 28,8 \mathbf{c}$ & 10,274 & $<0,001$ \\
\hline & Kuru dal & & & $9,6 \pm 2,0 \mathbf{a b}$ & $8,5 \pm 1,1 \mathbf{a}$ & $8,8 \pm 1,4 \mathbf{a b}$ & $14,2 \pm 3,2 \mathbf{b}$ & 10,320 & $<0,001$ \\
\hline & Canlı dal & $0,8 \pm 0,1 \mathbf{a}$ & $1,3 \pm 0,1 \mathbf{a}$ & $40,8 \pm 6,3 \mathbf{b}$ & $36,8 \pm 4,0 \mathbf{b}$ & $54,4 \pm 12,4 \mathbf{b c}$ & $74,8 \pm 11,4 \mathbf{c}$ & 15,441 & $<0,001$ \\
\hline & Gövde & $1,2 \pm 0,5 \mathbf{a}$ & $6,0 \pm 1,1 \mathbf{a}$ & $52,3 \pm 8,1 \mathbf{b}$ & $55,1 \pm 7,6 \mathbf{b}$ & $63,5 \pm 12,2 \mathbf{b}$ & $90,9 \pm 15,4 \mathbf{c}$ & 13,799 & $<0,001$ \\
\hline & Kabuk & $1,7 \pm 0,6 \mathbf{a}$ & $7,3 \pm 1,0 \mathbf{a}$ & $24,9 \pm 4,1 \mathbf{b}$ & $28,1 \pm 4,2 \mathbf{b}$ & $25,5 \pm 3,5 \mathbf{b}$ & $39,7 \pm 8,9 \mathbf{b}$ & 8,640 & $<0,001$ \\
\hline & Kök & $1,7 \pm 0,6 \mathbf{a}$ & $8,1 \pm 1,6 \mathbf{a}$ & $35,7 \pm 9,3 \mathbf{b}$ & $43,1 \pm 10,2 \mathbf{b}$ & $28,9 \pm 4,6 \mathbf{b}$ & $41,9 \pm 6,7 \mathbf{b}$ & 6,581 & $<0,001$ \\
\hline \multirow{6}{*}{$\mathrm{P}$} & İbre & $1,50 \pm 0,65 \mathbf{a}$ & $6,82 \pm 1,11 \mathbf{b}$ & $8,4 \pm 1,2 \mathbf{b}$ & $9,1 \pm 1,1 \mathbf{b}$ & $12,2 \pm 1,6 \mathbf{b}$ & $18,7 \pm 3,4 \mathrm{c}$ & 9,784 & $<0,001$ \\
\hline & Kuru dal & & & $0,5 \pm 0,1 \mathbf{a b}$ & $0,3 \pm 0,04 \mathbf{a}$ & $0,5 \pm 0,1 \mathbf{a b}$ & $0,6 \pm 0,09 \mathbf{b}$ & 11,246 & $<0,001$ \\
\hline & Canlı dal & $0,08 \pm 0,02 \mathbf{a}$ & $0,15 \pm 0,02 \mathbf{a}$ & $3,9 \pm 0,7 \mathbf{b}$ & $3,7 \pm 0,4 \mathbf{b}$ & $7,5 \pm 2,2 \mathbf{c}$ & $8,5 \pm 1,3 \mathbf{c}$ & 10,685 & $<0,001$ \\
\hline & Gövde & $0,09 \pm 0,05 \mathbf{a}$ & $0,45 \pm 0,11 \mathbf{a}$ & $2,3 \pm 0,3 \mathbf{a b}$ & $3,3 \pm 0,8 \mathbf{b c}$ & $5,5 \pm 0,9 \mathbf{c d}$ & $6,7 \pm 1,9 \mathbf{d}$ & 7,438 & $<0,001$ \\
\hline & Kabuk & $0,16 \pm 0,07 \mathbf{a}$ & $0,77 \pm 0,13 \mathbf{a b}$ & $1,6 \pm 0,2 \mathbf{b c}$ & $2,2 \pm 0,3 \mathbf{c d}$ & $2,1 \pm 0,4 \mathbf{c d}$ & $3,4 \pm 0,9 \mathbf{d}$ & 6,394 & $<0,001$ \\
\hline & Kök & $0,19 \pm 0,07 \mathbf{a}$ & $0,93 \pm 0,16 \mathbf{a b}$ & $3,7 \pm 0,7 \mathrm{bc}$ & $4,6 \pm 0,8 \mathbf{c}$ & $6,1 \pm 1,1 \mathbf{c}$ & $9,8 \pm 2,0 \mathbf{d}$ & 10,603 & $<0,001$ \\
\hline \multirow{6}{*}{ K } & İbre & $7,2 \pm 2,2 \mathbf{a}$ & $37,0 \pm 5,7 \mathbf{b}$ & $47,8 \pm 9,8 \mathbf{b}$ & $49,1 \pm 11,2 \mathbf{b c}$ & $77,5 \pm 15,8 \mathbf{b c}$ & $100,1 \pm 21,2 \mathbf{c}$ & 16,262 & $<0,001$ \\
\hline & Kuru dal & & & $3,2 \pm 0,5 \mathbf{a}$ & $2,2 \pm 0,3 \mathbf{a}$ & $3,3 \pm 0,6 \mathbf{a}$ & $5,4 \pm 1,4 \mathbf{b}$ & 8,702 & $<0,001$ \\
\hline & Canlı dal & $0,4 \pm 0,1 \mathbf{a}$ & $0,8 \pm 0,1 \mathbf{a}$ & $29,9 \pm 5,1 \mathbf{b}$ & $32,9 \pm 6,5 \mathbf{b}$ & $51,0 \pm 14,4 \mathbf{b c}$ & $80,1 \pm 20,7 \mathbf{c}$ & 21,307 & $<0,001$ \\
\hline & Gövde & $0,8 \pm 0,3 \mathbf{a}$ & $4,5 \pm 1,0 \mathbf{b}$ & $40,3 \pm 8,7 \mathbf{c}$ & $46,2 \pm 11,8 \mathbf{c}$ & $54,9 \pm 12,4 \mathbf{c}$ & $108,1 \pm 31,2 \mathbf{c}$ & 40,222 & $<0,001$ \\
\hline & Kabuk & $0,6 \pm 0,2 \mathbf{a}$ & $3,8 \pm 0,8 \mathbf{b}$ & $11,2 \pm 1,7 \mathbf{c}$ & $16,6 \pm 3,9 \mathbf{c}$ & $15,8 \pm 3,6 \mathbf{c}$ & $28,3 \pm 10,7 \mathbf{c}$ & 26,597 & $<0,001$ \\
\hline & Kök & $1,2 \pm 0,3 \mathbf{a}$ & $6,4 \pm 1,0 \mathbf{a}$ & $32,2 \pm 5,7 \mathbf{b}$ & $41,3 \pm 8,9 \mathbf{b c}$ & $41,3 \pm 8,4 \mathbf{b c}$ & $65,3 \pm 16,2 \mathrm{c}$ & 7,325 & $<0,001$ \\
\hline \multirow{6}{*}{$\mathrm{Ca}$} & İbre & $5,8 \pm 2,6 \mathbf{a}$ & $41,6 \pm 13,9 \mathbf{b}$ & $30,4 \pm 2,8 \mathbf{a b}$ & $40,0 \pm 6,9 \mathbf{b}$ & $38,6 \pm 10,3 \mathbf{b}$ & $47,7 \pm 9,3 \mathbf{b}$ & 2,710 & $<0,05$ \\
\hline & Kuru dal & & & $24,8 \pm 3,8 \mathbf{a b}$ & $23,2 \pm 3,6 \mathbf{a}$ & $38,6 \pm 6,7 \mathbf{b}$ & $36,5 \pm 7,9 \mathbf{a b}$ & 12,464 & $<0,001$ \\
\hline & Canlı dal & $0,9 \pm 0,3 \mathbf{a}$ & $1,9 \pm 0,5 \mathbf{a}$ & $70,6 \pm 8,1 \mathbf{b}$ & $65,7 \pm 10,0 \mathbf{b}$ & $137,6 \pm 37,8 \mathbf{c}$ & $136,9 \pm 29,7 \mathbf{c}$ & 9,301 & $<0,001$ \\
\hline & Gövde & $0,7 \pm 0,2 \mathbf{a}$ & $7,2 \pm 2,3 \mathbf{a}$ & $64,0 \pm 9,4 \mathbf{a b}$ & $95,4 \pm 17,0 \mathbf{b c}$ & $118,6 \pm 30,6 \mathbf{b c}$ & $159,3 \pm 38,4 \mathbf{c}$ & 8,352 & $<0,001$ \\
\hline & Kabuk & $1,2 \pm 0,5 \mathbf{a}$ & $9,7 \pm 3,6 \mathbf{a}$ & $60,4 \pm 15,2 \mathbf{b}$ & $70,1 \pm 11,4 \mathbf{b}$ & $67,3 \pm 18,0 \mathbf{b}$ & $99,2 \pm 29,1 \mathbf{b}$ & 5,355 & $<0,01$ \\
\hline & Kök & $1,1 \pm 0,4 \mathbf{a}$ & $6,0 \pm 1,6 \mathbf{a}$ & $30,2 \pm 5,0 \mathbf{b}$ & $33,8 \pm 5,0 \mathbf{b}$ & $37,4 \pm 9,2 \mathbf{b}$ & $46,9 \pm 9,0 \mathbf{b}$ & 9,043 & $<0,001$ \\
\hline \multirow{6}{*}{$\mathrm{Mg}$} & İbre & $2,31 \pm 0,93 \mathbf{a}$ & $10,22 \pm 2,55 \mathbf{b}$ & $12,2 \pm 1,1 \mathbf{b c}$ & $17,5 \pm 3,1 \mathrm{c}$ & $12,2 \pm 1,6 \mathbf{b c}$ & $18,5 \pm 2,6 \mathbf{c}$ & 6,566 & $<0,001$ \\
\hline & Kuru dal & & & $2,6 \pm 0,3 \mathbf{a}$ & $2,6 \pm 0,4 \mathbf{a}$ & $2,8 \pm 0,4 \mathbf{a}$ & $3,5 \pm 0,5 \mathbf{a}$ & 14,827 & $>0,05$ \\
\hline & Canlı dal & $0,18 \pm 0,03 \mathbf{a}$ & $0,28 \pm 0,05 \mathbf{a}$ & $10,3 \pm 2,0 \mathbf{b}$ & $11,1 \pm 1,9 \mathbf{b}$ & $16,2 \pm 3,6 \mathbf{b c}$ & $20,8 \pm 3,0 \mathbf{c}$ & 13,947 & $<0,001$ \\
\hline & Gövde & $0,37 \pm 0,20 \mathbf{a}$ & $1,70 \pm 0,55 \mathbf{a}$ & $19,4 \pm 4,5 \mathbf{b}$ & $25,5 \pm 7,3 \mathbf{b}$ & $25,2 \pm 3,7 \mathbf{b}$ & $42,2 \pm 9,1 \mathbf{c}$ & 8,269 & $<0,001$ \\
\hline & Kabuk & $0,30 \pm 0,11 \mathbf{a}$ & $1,63 \pm 0,45 \mathbf{a b}$ & $3,9 \pm 0,6 \mathbf{b c}$ & $6,4 \pm 1,1$ cd & $5,1 \pm 0,7 \mathbf{c}$ & $8,1 \pm 1,7 \mathbf{d}$ & 8,805 & $<0,001$ \\
\hline & Kök & $0,42 \pm 0,15 \mathbf{a}$ & $1,52 \pm 0,42 \mathbf{a}$ & $9,8 \pm 1,8 \mathbf{b}$ & $11,3 \pm 2,7 \mathbf{b}$ & $11,0 \pm 1,9 \mathbf{b}$ & $11,8 \pm 1,6 \mathbf{b}$ & 8,975 & $<0,001$ \\
\hline \multirow{6}{*}{$\mathrm{S}$} & İbre & $1,68 \pm 0,55 \mathbf{a}$ & $7,39 \pm 1,32 \mathbf{b}$ & $8,6 \pm 1,3 \mathbf{b c}$ & $11,2 \pm 2,2 \mathbf{b c}$ & $13,1 \pm 1,8 \mathbf{c d}$ & $17,6 \pm 2,4 \mathbf{d}$ & 8,910 & $<0,001$ \\
\hline & Kuru dal & & & $1,8 \pm 0,5 \mathbf{a}$ & $2,1 \pm 0,4 \mathbf{a}$ & $2,0 \pm 0,4 \mathbf{a}$ & $2,7 \pm 0,7 \mathbf{a}$ & 6,280 & $>0,05$ \\
\hline & Canlı dal & $0,09 \pm 0,01 \mathbf{a}$ & $0,24 \pm 0,05 \mathbf{a}$ & $5,7 \pm 0,9 \mathbf{b c}$ & $3,8 \pm 0,7 \mathbf{b}$ & $9,5 \pm 4,7 \mathbf{b c}$ & $8,7 \pm 1,3 \mathbf{c}$ & 14,786 & $<0,001$ \\
\hline & Gövde & $0,09 \pm 0,02 \mathbf{a}$ & $1,16 \pm 0,29 \mathbf{b}$ & $7,2 \pm 3,9 \mathbf{c}$ & $6,6 \pm 1,8 \mathbf{c}$ & $12,2 \pm 5,9 \mathbf{c}$ & $11,8 \pm 5,6 \mathbf{c}$ & 13,286 & $<0,001$ \\
\hline & Kabuk & $0,13 \pm 0,03 \mathbf{a}$ & $1,07 \pm 0,26 \mathbf{a}$ & $3,9 \pm 0,8 \mathbf{b}$ & $5,2 \pm 0,6 \mathbf{b}$ & $3,9 \pm 1,0 \mathbf{b}$ & $6,3 \pm 1,5 \mathbf{b}$ & 7,276 & $<0,001$ \\
\hline & Kök & $0,28 \pm 0,08 \mathbf{a}$ & $2,36 \pm 0,55 \mathbf{a}$ & $8,7 \pm 1,9 \mathbf{b}$ & $10,0 \pm 1,7 \mathbf{b}$ & $10,1 \pm 2,5 \mathbf{b}$ & $11,7 \pm 2,4 \mathbf{b}$ & 6,681 & $<0,001$ \\
\hline & İbre & $0,11 \pm 0,03 \mathbf{a}$ & $0,62 \pm 0,08 \mathbf{b}$ & $0,73 \pm 0,08 \mathbf{b}$ & $0,81 \pm 0,11 \mathbf{b}$ & $0,70 \pm 0,12 \mathbf{b}$ & $1,32 \pm 0,26 \mathbf{c}$ & 7,346 & $<0,001$ \\
\hline & Kuru dal & & & $0,33 \pm 0,05 \mathbf{a}$ & $0,38 \pm 0,05 \mathbf{a}$ & $0,36 \pm 0,05 \mathbf{a}$ & $0,65 \pm 0,12 \mathbf{b}$ & 14,287 & $<0,001$ \\
\hline $\mathrm{Na}$ & Canlı dal & $0,01 \pm 0,002 \mathbf{a}$ & $0,04 \pm 0,007 \mathbf{a}$ & $0,91 \pm 0,12 \mathbf{b}$ & $1,13 \pm 0,17 \mathbf{b}$ & $1,51 \pm 0,25 \mathbf{b}$ & $2,35 \pm 0,46 \mathbf{c}$ & 14,001 & $<0,001$ \\
\hline & Gövde & $0,03 \pm 0,01 \mathbf{a}$ & $0,26 \pm 0,06 \mathbf{a}$ & $2,57 \pm 0,46 \mathbf{b}$ & $3,79 \pm 0,69 \mathbf{b}$ & $3,84 \pm 0,52 \mathbf{b}$ & $6,73 \pm 1,28 \mathbf{c}$ & 13,604 & $<0,001$ \\
\hline & Kabuk & $0,02 \pm 0,01 \mathbf{a}$ & $0,12 \pm 0,02 \mathbf{a}$ & $0,63 \pm 0,08 \mathbf{b}$ & $1,06 \pm 0,16 \mathbf{c d}$ & $0,77 \pm 0,10 \mathbf{b c}$ & $1,15 \pm 0,20 \mathbf{d}$ & 14,257 & $<0,001$ \\
\hline & Kök & $0,06 \pm 0,03 \mathbf{a}$ & $0,23 \pm 0,04 \mathbf{a}$ & $1,33 \pm 0,22 \mathbf{b}$ & $1,65 \pm 0,23 \mathbf{b}$ & $1,38 \pm 0,26 \mathbf{b}$ & $2,07 \pm 0,48 \mathbf{b}$ & 8,717 & $<0,001$ \\
\hline & İbre & $0,21 \pm 0,06 \mathbf{a}$ & $1,31 \pm 0,33 \mathbf{b}$ & $1,39 \pm 0,17 \mathbf{b}$ & $1,56 \pm 0,18 \mathbf{b}$ & $1,68 \pm 0,25 \mathbf{b}$ & $2,54 \pm 0,44 \mathbf{c}$ & 6,936 & $<0,001$ \\
\hline & Kuru dal & & & $0,99 \pm 0,19 \mathbf{a}$ & $0,95 \pm 0,17 \mathbf{a}$ & $1,43 \pm 0,29 \mathbf{a b}$ & $2,00 \pm 0,59 \mathbf{b}$ & 6,983 & $<0,001$ \\
\hline $\mathrm{Fe}$ & Canlı dal & $0,04 \pm 0,005 \mathbf{a}$ & $0,09 \pm 0,01 \mathbf{a}$ & $2,01 \pm 0,32 \mathbf{b}$ & $2,29 \pm 0,51 \mathbf{b}$ & $3,48 \pm 0,46 \mathbf{b}$ & $5,45 \pm 0,99 \mathbf{c}$ & 15,501 & $<0,001$ \\
\hline & Gövde & $0,06 \pm 0,02 \mathbf{a}$ & $0,44 \pm 0,13 \mathbf{a}$ & $2,64 \pm 0,65 \mathbf{b}$ & $5,70 \pm 2,42 \mathbf{b c}$ & $8,70 \pm 3,29 \mathbf{c}$ & $7,43 \pm 1,74 \mathbf{c}$ & 10,974 & $<0,001$ \\
\hline & Kabuk & $0,06 \pm 0,02 \mathbf{a}$ & $0,30 \pm 0,07 \mathbf{a b}$ & $1,38 \pm 0,25 \mathbf{b c}$ & $2,35 \pm 0,72 \mathbf{c}$ & $1,67 \pm 0,26 \mathbf{c}$ & $2,27 \pm 0,45 \mathbf{c}$ & 5,993 & $<0,001$ \\
\hline & Kök & $0,17 \pm 0,06 \mathbf{a}$ & $0,81 \pm 0,14 \mathbf{a}$ & $2,44 \pm 0,40 \mathbf{b}$ & $3,65 \pm 0,60 \mathbf{b}$ & $3,12 \pm 0,67 \mathbf{b}$ & $3,31 \pm 0,67 \mathbf{b}$ & 8,146 & $<0,001$ \\
\hline & İbre & $0,06 \pm 0,02 \mathbf{a}$ & $0,42 \pm 0,13 \mathbf{b}$ & $0,48 \pm 0,10 \mathbf{b}$ & $0,45 \pm 0,08 \mathbf{b}$ & $0,58 \pm 0,11 \mathbf{b c}$ & $0,84 \pm 0,17 \mathbf{c}$ & 4,486 & $<0,01$ \\
\hline & Kuru dal & & & $0,16 \pm 0,03 \mathbf{a b}$ & $0,12 \pm 0,02 \mathbf{a}$ & $0,16 \pm 0,02 \mathbf{a b}$ & $0,21 \pm 0,02 \mathbf{b}$ & 14,013 & $<0,001$ \\
\hline $\mathrm{Zn}$ & Canlı dal & $0,01 \pm 0,003 \mathbf{a}$ & $0,02 \pm 0,005 \mathbf{a}$ & $0,50 \pm 0,06 \mathbf{b}$ & $0,47 \pm 0,06 \mathbf{b}$ & $0,93 \pm 0,26 \mathbf{c}$ & $1,04 \pm 0,14 \mathbf{c}$ & 12,273 & $<0,001$ \\
\hline & Gövde & $0,02 \pm 0,008 \mathbf{a}$ & $0,09 \pm 0,01 \mathbf{a}$ & $1,29 \pm 0,52 \mathbf{a b}$ & $1,54 \pm 0,41 \mathbf{a b}$ & $2,33 \pm 1,22 \mathbf{b}$ & $1,88 \pm 0,31 \mathbf{b}$ & 2,820 & $<0,05$ \\
\hline & Kabuk & $0,01 \pm 0,007 \mathbf{a}$ & $0,06 \pm 0,01 \mathbf{a b}$ & $0,26 \pm 0,04 \mathbf{b c}$ & $0,39 \pm 0,07 \mathbf{c}$ & $0,42 \pm 0,13 \mathbf{c}$ & $0,46 \pm 0,08 \mathbf{c}$ & 6,508 & $<0,001$ \\
\hline & Kök & $0,01 \pm 0,006 \mathbf{a}$ & $0,10 \pm 0,03 \mathbf{a}$ & $0,43 \pm 0,07 \mathbf{b}$ & $0,42 \pm 0,05 \mathbf{b}$ & $0,44 \pm 0,09 \mathbf{b}$ & $0,66 \pm 0,11 \mathbf{c}$ & 10,439 & $<0,001$ \\
\hline & İbre & $0,22 \pm 0,13 \mathbf{a}$ & $1,52 \pm 0,39 \mathbf{a}$ & $1,87 \pm 0,59 \mathbf{a}$ & $1,24 \pm 0,22 \mathbf{a}$ & $2,23 \pm 0,54 \mathbf{a}$ & $2,06 \pm 0,85 \mathbf{a}$ & 1,789 & $>0,05$ \\
\hline & Kuru dal & & & $0,35 \pm 0,08 \mathbf{a}$ & $0,26 \pm 0,02 \mathbf{a}$ & $0,42 \pm 0,09 \mathbf{a}$ & $0,34 \pm 0,09 \mathbf{a}$ & 7,810 & $>0,05$ \\
\hline $\mathrm{Mn}$ & Canlı dal & $0,01 \pm 0,002 \mathbf{a}$ & $0,04 \pm 0,008 \mathbf{a}$ & $1,27 \pm 0,38 \mathbf{b}$ & $0,91 \pm 0,10 \mathbf{b}$ & $2,21 \pm 0,63 \mathbf{b}$ & $1,93 \pm 0,78 \mathbf{b}$ & 11,589 & $<0,001$ \\
\hline & Gövde & $0,02 \pm 0,013 \mathbf{a}$ & $0,18 \pm 0,02 \mathbf{a}$ & $2,30 \pm 0,62 \mathbf{b}$ & $2,04 \pm 0,24 \mathbf{b}$ & $3,27 \pm 0,72 \mathbf{b}$ & $3,60 \pm 0,93 \mathbf{b}$ & 7,158 & $<0,001$ \\
\hline & Kabuk & $0,01 \pm 0,006 \mathbf{a}$ & $0,10 \pm 0,02 \mathbf{a}$ & $0,57 \pm 0,20 \mathbf{b}$ & $0,58 \pm 0,07 \mathbf{b}$ & $0,53 \pm 0,12 \mathbf{b}$ & $0,58 \pm 0,13 \mathbf{b}$ & 4,906 & $<0,01$ \\
\hline & Kök & $0,017 \pm 0,006 \mathbf{a}$ & $0,13 \pm 0,02 \mathbf{a}$ & $0,82 \pm 0,27 \mathbf{b}$ & $0,88 \pm 0,09 \mathbf{b}$ & $0,82 \pm 0,19 \mathbf{b}$ & $1,02 \pm 0,32 \mathbf{b}$ & 4,443 & $<0,01$ \\
\hline & İbre & $0,06 \pm 0,02 \mathbf{a}$ & $0,27 \pm 0,06 \mathbf{b}$ & $0,30 \pm 0,06 \mathbf{b c}$ & $0,29 \pm 0,03 \mathbf{b c}$ & $0,36 \pm 0,04 \mathbf{b c}$ & $0,45 \pm 0,05 \mathbf{c}$ & 5,982 & $<0,001$ \\
\hline & Kuru dal & & & $0,12 \pm 0,02 \mathbf{a}$ & $0,12 \pm 0,01 \mathbf{a}$ & $0,14 \pm 0,01 \mathbf{a b}$ & $0,18 \pm 0,02 \mathbf{b}$ & 19,458 & $<0,001$ \\
\hline $\mathrm{Cu}$ & Canlı dal & $0,008 \pm 0,001 \mathbf{a}$ & $0,01 \pm 0,002 \mathbf{a}$ & $0,44 \pm 0,08 \mathbf{b}$ & $0,45 \pm 0,05 \mathbf{b}$ & $0,77 \pm 0,15 \mathbf{c}$ & $0,83 \pm 0,11 \mathbf{c}$ & 16,142 & $<0,001$ \\
\hline & Gövde & $0,03 \pm 0,01 \mathbf{a}$ & $0,13 \pm 0,03 \mathbf{a}$ & $1,39 \pm 0,30 \mathbf{b}$ & $1,67 \pm 0,26 \mathbf{b}$ & $2,18 \pm 0,34 \mathbf{b c}$ & $2,81 \pm 0,40 \mathbf{c}$ & 15,949 & $<0,001$ \\
\hline & Kabuk & $0,01 \pm 0,005 \mathbf{a}$ & $0,05 \pm 0,01 \mathbf{a}$ & $0,28 \pm 0,05 \mathbf{b}$ & $0,35 \pm 0,05 \mathbf{b}$ & $0,37 \pm 0,05 \mathbf{b c}$ & $0,50 \pm 0,07 \mathbf{c}$ & 15,067 & $<0,001$ \\
\hline & Kök & $0,03 \pm 0,01 \mathbf{a}$ & $0,10 \pm 0,02 \mathbf{a}$ & $0,53 \pm 0,09 \mathbf{b}$ & $0,58 \pm 0,06 \mathbf{b c}$ & $0,59 \pm 0,07 \mathbf{b c}$ & $0,76 \pm 0,09 \mathbf{c}$ & 16,706 & $<0,001$ \\
\hline
\end{tabular}

Satırlardaki aynı harfler aralarında fark bulunmayan $(\mathrm{p}>0,05)$ benzer grupları göstermektedir, SH: standart hata, $p$ : önem düzeyi 
Tablo 8. Ekosistemin farklı bileșenlerinde depolanan besin stoklarının meșcere tiplerine göre değișimi (kg/ha) Table 8. Change in nutrient stocks stored in different components of ecosystem according to stand types ( $\mathrm{kg} / \mathrm{ha})$

\begin{tabular}{|c|c|c|c|c|c|c|c|c|c|}
\hline & \multirow{2}{*}{ Bileşenler } & \multicolumn{6}{|c|}{ Meşcere tipleri (Ort.(\%)) } & \multirow{2}{*}{$\begin{array}{c}F \\
\text { Oran1 }\end{array}$} & \multirow[b]{2}{*}{$\mathrm{p}$} \\
\hline & & Çka & Çka3 & Çkb2 & Çkb3 & Çkc2 & Çkc3 & & \\
\hline \multirow{6}{*}{$\mathrm{N}$} & Ağaç & $24,5(0,25)$ a & $90,1(1,0) \mathbf{a}$ & $249,8(2,7) \mathbf{b}$ & $277,9(3,30) \mathbf{b}$ & $299,2(3,40) \mathbf{b}$ & $447,1(5,50) \mathbf{c}$ & 13,93 & $<0,001$ \\
\hline & Çalı & $1,5(0,01) \mathbf{a}$ & $16,7(0,18)$ a & $3,3(0,03) \mathbf{a}$ & $5,7(0,07) \mathbf{a}$ & $7,2(0,08) \mathbf{a}$ & $1,3(0,01) \mathbf{a}$ & 0,68 & $>0,05$ \\
\hline & $\mathrm{Ot}$ & $21,1(0,22) \mathbf{c}$ & $18,8(0,21) \mathbf{b c}$ & $3,2(0,03) \mathbf{a}$ & $4,1(0,05) \mathbf{a b}$ & $7,6(0,09) \mathbf{a}$ & $5,6(0,07) \mathbf{a}$ & 3,85 & $<0,01$ \\
\hline & Ölü örtü & - & $23,6(0,26) \mathbf{a}$ & $118,7(1,27) \mathbf{b}$ & $156,6(1,86) \mathbf{b}$ & $139,5(1,59) \mathbf{b}$ & $188,0(2,31) \mathbf{b}$ & 8,98 & $<0,001$ \\
\hline & Toprak & $9604(99,5) \mathbf{a}$ & $8855(98,3)$ a & $8941(96,0) \mathbf{a}$ & $7986(94,72) a$ & $8326(94,83) \mathbf{a}$ & $7489(92,10) \mathbf{a}$ & 0,33 & $>0,05$ \\
\hline & Toplam & $9651(100) \mathbf{a}$ & $9004(100) \mathbf{a}$ & $9316(100) \mathbf{a}$ & 8431(100) a & $8780(100) \mathbf{a}$ & $8131(100) \mathbf{a}$ & 0,18 & $>0,05$ \\
\hline \multirow{6}{*}{$\mathrm{P}$} & Ağaç & $2,0(3,72) \mathbf{a}$ & $9,1(11,76) \mathbf{a b}$ & $20,7(25,27)$ bc & $23,5(29,34) \mathbf{c}$ & $34,2(36,23) \mathbf{c}$ & $47,9(31,16) \mathbf{d}$ & 12,15 & $<0,001$ \\
\hline & Çalı & $0,1(0,18) \mathbf{a}$ & $1,7(2,20) \mathbf{a}$ & $0,4(0,49) \mathbf{a}$ & $0,8(1,00) \mathbf{a}$ & $1,0(1,06) \mathbf{a}$ & $0,1(0,06) \mathbf{a}$ & 1,18 & $>0,05$ \\
\hline & Ot & $1,7(3,16) \mathbf{b}$ & $1,7(2,20) \mathbf{b}$ & $0,2(0,24) \mathbf{a}$ & $0,4(0,50) \mathbf{a}$ & $0,8(0,85) \mathbf{a}$ & $0,4(0,26) \mathbf{a}$ & 3,92 & $<0,01$ \\
\hline & Ölü örtü & - & $1,3(1,68) \mathbf{a}$ & $8,5(10,38) \mathbf{b}$ & $9,8(12,23) \mathbf{b}$ & $10,2(10,80) \mathbf{b}$ & $15,2(9,89) \mathbf{c}$ & 11,90 & $<0,001$ \\
\hline & Toprak & $49,8(92,74) \mathbf{a}$ & $63,4(81,91) \mathbf{a}$ & $51,9(63,37) \mathbf{a}$ & $45,4(56,68) a$ & $48,4(51,27) \mathbf{a}$ & $89,8(58,42) \mathbf{a}$ & 1,71 & $>0,05$ \\
\hline & Toplam & $53,7(100) \mathbf{a}$ & $77,4(100) \mathbf{a}$ & $81,9(100) \mathbf{a}$ & $80,1(100)$ a & $94,4(100) \mathbf{a}$ & $153,7(100) \mathbf{b}$ & 5,96 & $<0,001$ \\
\hline \multirow{6}{*}{ K } & Ağaç & $10,4(0,44) \mathbf{a}$ & $52,8(2,64) \mathbf{a b}$ & $164,9(9,86) \mathbf{b c}$ & $188,5(8,33) \mathbf{b c}$ & c $244,0(13,97) \mathbf{c}$ & $387,6(20,88) \mathbf{d}$ & 7,44 & $<0,001$ \\
\hline & Çalı & $0,7(0,03) \mathbf{a}$ & $11,7(0,58) \mathbf{a}$ & $2,2(0,13) \mathbf{a}$ & $4,2(0,18) \mathbf{a}$ & $13,1(0,75) \mathbf{a}$ & $0,9(0,05) \mathbf{a}$ & 0,85 & $>0,05$ \\
\hline & $\mathrm{Ot}$ & $12,3(0,52) \mathbf{b}$ & $10,7(0,53) \mathbf{b}$ & $1,4(0,08) \mathbf{a}$ & $2,0(0,09) \mathbf{a}$ & $3,0(0,17) \mathbf{a}$ & $2,4(0,13) \mathbf{a}$ & 5,02 & $<0,01$ \\
\hline & Ölü örtü & - & $6,2(0,31) \mathbf{a}$ & $36,9(2,2) \mathbf{b}$ & $37,4(1,65) \mathbf{b}$ & $46,6(2,67) \mathbf{b}$ & $69,7(3,75) \mathbf{c}$ & 6,56 & $<0,001$ \\
\hline & Toprak & $2323(98,98) \mathbf{a}$ & $1921(95,91) \mathbf{a}$ & $1467(87,69) \mathbf{a}$ & $2031(89,75) \mathbf{a}$ & $1440(82,47)$ a & $1396(75,21) \mathbf{a}$ & 1,02 & $>0,05$ \\
\hline & Toplam & $2347(100) \mathbf{a}$ & $2003(100) \mathbf{a}$ & $1673(100) \mathbf{a}$ & $2263(100) \mathbf{a}$ & $1746(100) \mathbf{a}$ & $1856(100) \mathbf{a}$ & 0,56 & $>0,05$ \\
\hline \multirow{6}{*}{$\mathrm{Ca}$} & Ağaç & $9,8(0,02) \mathbf{a}$ & $66,6(0,20) \mathbf{a}$ & $280,8(1,58) \mathbf{b}$ & $328,4(1,22) \mathbf{b c}$ & $438,3(3,38) \mathbf{b c}$ & $526,6(2,77) \mathrm{c}$ & 8,44 & $<0,001$ \\
\hline & Çalı & $3,2(0,007) \mathbf{a}$ & $14,4(0,04) \mathbf{a}$ & $6,3(0,03) \mathbf{a}$ & $22,0(0,08) \mathbf{a}$ & $7,3(0,06) \mathbf{a}$ & $3,6(0,68) \mathbf{a}$ & 0,46 & $>0,05$ \\
\hline & Ot & $26,5(0,06) \mathbf{a}$ & $38,4(0,11) \mathbf{a}$ & $3,3(0,02) \mathbf{a}$ & $11,1(0,04) \mathbf{a}$ & $8,4(0,06) \mathbf{a}$ & $11,1(0,06) \mathbf{a}$ & 2,08 & $>0,05$ \\
\hline & Ölü örtü & - & $98,2(0,29) \mathbf{a}$ & $279,6(1,58) \mathbf{b}$ & $335,9(1,25) \mathbf{b}$ & $287,1(2,21) \mathbf{b}$ & $515,4(2,71) \mathbf{c}$ & 11,05 & $<0,001$ \\
\hline & Toprak & $44170(99,91) \mathbf{c}$ & $33538(99,36) \mathbf{b c}$ & $17148(96,78) \mathbf{a b}$ & $26152(97,40) \mathbf{a b c}$ & $12218(94,28) \mathbf{a}$ & $17975(94,45) \mathbf{a b}$ & 3,48 & $<0,05$ \\
\hline & Toplam & $44209(100) \mathbf{c}$ & $33755(100) \mathbf{b c}$ & $17718(100) \mathbf{a b}$ & 26850(100) abc & $12959(100) \mathbf{a}$ & 19032(100) ab & 3,27 & $<0,05$ \\
\hline \multirow{6}{*}{$\mathrm{Mg}$} & Ağaç & $3,6(0,12) \mathbf{a}$ & $15,3(0,50) \mathbf{a}$ & $58,4(1,05) \mathbf{b}$ & $74,7(1,02) \mathbf{b c}$ & $72,8(3,96) \mathbf{b c}$ & $105,2(3,08) \mathbf{c}$ & 11,10 & $<0,001$ \\
\hline & Çalı & $0,2(0,01) \mathbf{a}$ & $3,1(0,10)$ a & $0,5(0,01)$ a & $1,0(0,01) \mathbf{a}$ & $1,5(0,08) \mathbf{a}$ & $0,3(0,01) \mathbf{a}$ & 0,56 & $>0,05$ \\
\hline & Ot & $8,1(0,26) \mathbf{c}$ & $6,0(0,20) \mathbf{b c}$ & $1,1(0,02) \mathbf{a}$ & $1,5(0,02) \mathbf{a b}$ & $2,7(0,15) \mathbf{a b}$ & $1,5(0,04) \mathbf{a b}$ & 3,92 & $<0,01$ \\
\hline & Ölü örtü & - & $7,0(0,23) \mathbf{a b}$ & $28,8(0,52) \mathbf{b c}$ & $46,6(0,64) \mathrm{cd}$ & $35,3(1,92) \mathbf{c}$ & $68,8(2,01) \mathbf{d}$ & 10,53 & $<0,001$ \\
\hline & Toprak & $3074(99,61) \mathbf{a}$ & $3017(98,98) \mathbf{a}$ & $5474(98,40) \mathbf{a}$ & $7203(98,31) \mathbf{a}$ & $1726(93,90) \mathbf{a}$ & $3239(94,85) \mathbf{a}$ & 0,63 & $>0,05$ \\
\hline & Toplam & $3086(100) \mathbf{a}$ & $3048(100) \mathbf{a}$ & $5563(100) \mathbf{a}$ & $7327(100) \mathbf{a}$ & $1838(100) \mathbf{a}$ & $3415(100) \mathbf{a}$ & 0,60 & $>0,05$ \\
\hline \multirow{6}{*}{$\mathrm{S}$} & Ağaç & $2,3(3,38) \mathbf{a}$ & $12,2(15,36) \mathbf{a}$ & $36,2(32,58) \mathbf{b}$ & $39,2(34,50) \mathbf{b}$ & $51,0(43,59) \mathbf{b}$ & $58,9(38,65) \mathbf{b}$ & 7,34 & $<0,001$ \\
\hline & Çalı & $0,2(0,29) \mathbf{a}$ & $2,2(2,77) \mathbf{a}$ & $0,3(0,27) \mathbf{a}$ & $0,7(0,62) \mathbf{a}$ & $0,7(0,60) \mathbf{a}$ & $0,1(0,06) \mathbf{a}$ & 0,96 & $>0,05$ \\
\hline & $\mathrm{Ot}$ & $3,8(5,58) \mathbf{b}$ & $2,6(3,27) \mathbf{b}$ & $0,4(0,36)$ a & $0,6(0,53) \mathbf{a}$ & $1,3(1,11) \mathbf{a}$ & $0,7(0,46) \mathbf{a}$ & 4,45 & $<0,01$ \\
\hline & Ölü örtü & - & $4,3(5,41) \mathbf{a}$ & $20,3(18,27) \mathbf{b}$ & $24,9(21,92) \mathbf{b}$ & $25,3(21,62) \mathbf{b}$ & $40,0(26,25) \mathbf{c}$ & 13,29 & $<0,001$ \\
\hline & Toprak & $61,7(90,60) \mathbf{a}$ & $57,9(72,92) \mathbf{a}$ & $53,7(48,33)$ a & $48,1(42,34) \mathbf{a}$ & $38,4(32,82) \mathbf{a}$ & $52,5(34,45) \mathbf{a}$ & 0,69 & $>0,05$ \\
\hline & Toplam & $68,1(100) \mathbf{a}$ & $79,4(100) \mathbf{a b}$ & $111,1(100) \mathbf{b}$ & $113,6(100) \mathbf{b}$ & $117,0(100) \mathbf{b c}$ & $152,4(100) \mathbf{c}$ & 5,46 & $<0,01$ \\
\hline & Ağaç & $0,26(0,06) \mathbf{a}$ & $1,29(0,20) \mathbf{a}$ & $6,53(2,85) \mathbf{b}$ & $8,85(4,51) \mathbf{b}$ & $8,57(5,29) \mathbf{b}$ & $14,29(9,10) \mathbf{c}$ & 15,37 & $<0,001$ \\
\hline & Çalı & $0,02(0,005) \mathbf{a}$ & $0,65(0,10) \mathbf{a}$ & $0,07(0,03) \mathbf{a}$ & $0,15(0,08) \mathbf{a}$ & $0,12(0,07) \mathbf{a}$ & $0,05(0,03) \mathbf{a}$ & 1,75 & $>0,05$ \\
\hline & Ot & $0,57(0,13) \mathbf{c}$ & $0,50(0,08) \mathbf{b c}$ & $0,08(0,03) \mathbf{a}$ & $0,17(0,09) \mathbf{a b}$ & $0,24(0,15) \mathbf{a b}$ & $0,15(0,09) \mathbf{a b}$ & 2,93 & $<0,05$ \\
\hline $\mathrm{Na}$ & Ölü örtü & - & $0,62(0,10) \mathbf{a}$ & $3,82(1,67) \mathbf{b}$ & $4,37(2,23) \mathbf{b}$ & $\quad 3,31(2,04) \mathbf{b}$ & $5,30(3,37) \mathbf{b}$ & 6,04 & $<0,001$ \\
\hline & Toprak & $433(99,8) \mathbf{b c}$ & $637(99,53) \mathbf{c}$ & $219(95,63) \mathbf{a b}$ & $183(93,37) \mathbf{a b}$ & $150(92,59) \mathbf{a b}$ & $137(87,26) \mathbf{a}$ & 3,81 & $<0,01$ \\
\hline & Toplam & $434(100) \mathbf{a b}$ & $640(100) \mathbf{b}$ & $229(100) \mathbf{a b}$ & $196(100) a$ & $162(100) \mathbf{a}$ & $157(100) \mathbf{a}$ & 3,21 & $<0,05$ \\
\hline & Ağaç & $0,56(0,98) \mathbf{a}$ & $2,98(3,80) \mathbf{a b}$ & $10,87(10,90) \mathbf{b c}$ & $16,52(15,49)$ cd & $20,11(14,03) \mathrm{d}$ & $23,03(12,13) \mathbf{d}$ & 10,00 & $<0,001$ \\
\hline & Çalı & $0,12(0,21) \mathbf{a}$ & $1,20(1,53) \mathbf{a}$ & $0,14(0,14) \mathbf{a}$ & $0,68(0,64) \mathbf{a}$ & $0,36(0,25)$ a & $0,13(0,07) \mathbf{a}$ & 0,92 & $>0,05$ \\
\hline E & $\mathrm{Ot}$ & $13,26(23,32) \mathbf{c}$ & $8,33(10,63) \mathbf{b c}$ & $1,30(1,30) \mathbf{a}$ & $2,30(2,16) \mathbf{a b}$ & $5,81(4,05) \mathbf{a}$ & $1,61(0,85) \mathbf{a}$ & 4,24 & $<0,01$ \\
\hline $\mathrm{Fe}$ & Ölü örtü & - & $10,60(13,53) \mathbf{a}$ & $68,87(69,06) \mathbf{b}$ & $72,79(68,24) \mathbf{b}$ & $88,64(61,86) \mathbf{b}$ & $148,82(78,41) \mathbf{c}$ & 9,83 & $<0,001$ \\
\hline & Toprak & $42,90(75,46) \mathbf{b}$ & $55,23(70,49) \mathbf{b}$ & $18,52(18,57) \mathbf{a}$ & $14,35(13,45) \mathbf{a}$ & $28,36(19,79)$ & $16,19(8,53) \mathbf{a}$ & 13,08 & $<0,001$ \\
\hline & Toplam & $56,85(100) \mathbf{a}$ & $78,35(100) \mathbf{a}$ & $99,72(100) \mathbf{a b}$ & $106,66(100) \mathbf{a b}$ & $143,29(100) \mathbf{b c}$ & $189,80(100) \mathbf{c}$ & 7,19 & $<0,001$ \\
\hline & Ağaç & $0,13(1,01) \mathbf{a}$ & $0,71(3,61) \mathbf{a b}$ & $3,14(19,89)$ bc & $3,42(24,46) \mathbf{c}$ & $4,88(26,38) \mathbf{c}$ & $5,11(27,19) \mathbf{c}$ & 5,70 & $<0,001$ \\
\hline & Çalı & $0,01(0,08) \mathbf{a}$ & $0,17(0,86) \mathbf{a}$ & $0,01(0,06) \mathbf{a}$ & $0,02(0,14) \mathbf{a}$ & $0,05(0,27) \mathbf{a}$ & $0,01(0,05) \mathbf{a}$ & 1,84 & $>0,05$ \\
\hline & Ot & $0,20(1,56) \mathbf{b}$ & $0,17(0,86) \mathbf{b}$ & $0,02(0,13)$ a & $0,03(0,21) \mathbf{a}$ & $0,08(0,43) \mathbf{a b}$ & $0,03(0,16) \mathbf{a}$ & 3,11 & $<0,05$ \\
\hline $\mathrm{Zn}$ & Ölü örtü & - & $0,20(1,02) \mathbf{a}$ & $1,13(7,16) \mathbf{b}$ & $1,14(8,15) \mathbf{b}$ & $1,25(6,76) \mathbf{b c}$ & $1,79(9,53) \mathbf{c}$ & 11,00 & $<0,001$ \\
\hline & Toprak & $12,47(97,19) \mathbf{a}$ & $18,37(93,49) \mathbf{a}$ & $11,47(72,64) \mathbf{a}$ & $9,35(66,88) \mathbf{a}$ & $12,22(66,05)$ a & $11,84(63,01) \mathbf{a}$ & 1,10 & $>0,05$ \\
\hline & Toplam & $12,83(100) \mathbf{a}$ & $19,65(100) \mathbf{a}$ & $15,79(100) \mathbf{a}$ & $13,98(100) \mathbf{a}$ & $18,50(100) \mathrm{a}$ & $18,79(100) \mathbf{a}$ & 0,76 & $>0,05$ \\
\hline & Ağaç & $0,29(0,12) \mathbf{a}$ & $1,99(0,50) \mathbf{a b}$ & $7,20(2,59) \mathbf{b c}$ & $5,94(2,75) \mathbf{b c}$ & $9,50(2,88) \mathbf{c}$ & $9,55(4,64) \mathbf{c}$ & 4,40 & $<0,01$ \\
\hline & Çalı & $0,02(0,008) \mathbf{a}$ & $0,53(0,13) \mathbf{a}$ & $0,06(0,02) \mathbf{a}$ & $0,14(0,06) \mathbf{a}$ & $0,05(0,01) \mathbf{a}$ & $0,01(0,005) \mathbf{a}$ & 1,49 & $>0,05$ \\
\hline & $\mathrm{Ot}$ & $0,78(0,31) \mathbf{b}$ & $0,59(0,15) \mathbf{b}$ & $0,08(0,03) \mathbf{a}$ & $0,12(0,05) \mathbf{a}$ & $0,28(0,08) \mathbf{a}$ & $0,11(0,05) \mathbf{a}$ & 4,11 & $<0,01$ \\
\hline $\mathrm{Mn}$ & Ölü örtü & - & $1,11(0,28) \mathbf{a}$ & $6,08(2,19) \mathbf{b}$ & $5,13(2,37) \mathbf{b}$ & $\quad 6,95(2,11) \mathbf{b}$ & $8,33(4,05) \mathbf{b}$ & 6,15 & $<0,001$ \\
\hline & Toprak & $247,1(99,60) \mathbf{a}$ & $396,8(98,93) \mathbf{a}$ & $264,3(95,14) \mathbf{a}$ & $204,9(94,73) \mathbf{a}$ & $312,6(94,90) \mathbf{a}$ & $187,7(91,25) \mathbf{a}$ & 1,03 & $>0,05$ \\
\hline & Toplam & $248,1(100) \mathbf{a}$ & $401,1(100) \mathbf{a}$ & $277,8(100) \mathbf{a}$ & $216,3(100) \mathbf{a}$ & $329,4(100) \mathbf{a}$ & $205,7(100) \mathbf{a}$ & 0,92 & $>0,05$ \\
\hline & Ağaç & $0,15(1,64) \mathbf{a}$ & $0,57(2,33) \mathbf{a}$ & $3,08(16,29) \mathbf{b}$ & $3,48(16,74) \mathbf{b}$ & $4,43(22,78) \mathbf{b c}$ & $5,56(25,01) \mathbf{c}$ & 15,75 & $<0,001$ \\
\hline & Çalı & $0,009(0,10) \mathbf{a}$ & $0,08(0,33) \mathbf{a}$ & $0,02(0,10) \mathbf{a}$ & $0,04(0,19) \mathbf{a}$ & $0,04(0,20) \mathbf{a}$ & $0,008(0,036) \mathbf{a}$ & 1,05 & $>0,05$ \\
\hline & $\mathrm{Ot}$ & $0,06(0,66) \mathbf{c}$ & $0,05(0,20) \mathbf{b c}$ & $0,007(0,04) \mathbf{a}$ & $0,01(0,05) \mathbf{a b}$ & $0,02(0,10) \mathbf{a b}$ & $0,01(0,04) \mathbf{a b}$ & 3,58 & $<0,01$ \\
\hline $\mathrm{Cu}$ & Ölü örtü & - & $0,13(0,53) \mathbf{a}$ & $0,57(3,01) \mathbf{b}$ & $0,68(3,27) \mathbf{b c}$ & $0,68(3,50) \mathbf{b c}$ & $0,97(4,36) \mathbf{c}$ & 13,90 & $<0,001$ \\
\hline & Toprak & $8,91(97,48) \mathbf{a}$ & $23,59(96,52) \mathbf{a}$ & $15,22(80,49) \mathbf{a}$ & $16,57(79,70) \mathbf{a}$ & $14,27(73,37)$ & $15,67(70,49) \mathbf{a}$ & 2,35 & $>0,05$ \\
\hline & Toplam & $9,14(100) \mathbf{a}$ & $24,44(100) \mathbf{a}$ & $18,91(100) \mathbf{a}$ & $20,79(100) \mathbf{a}$ & $19,45(100) \mathbf{a}$ & $22,23(100) \mathbf{a}$ & 2,02 & $>0,05$ \\
\hline
\end{tabular}

Satırlardaki aynı harfler aralarında fark bulunmayan $(\mathrm{p}>0,05)$ benzer grupları göstermektedir, SH: standart hata, p: önem düzeyi 
Ekosistemdeki P, S ve Fe stoğu Çkc3 meşcerelerinde, $\mathrm{Ca}$ ve $\mathrm{Na}$ stoğu ise Çka ve Çka3 meşcerelerinde en yüksek düzeydedir. Ekosistemde $\mathrm{S}$ ve Fe dışındaki besin stoklarının en önemli kısmını toprak oluşturmaktadir. Kükürt stoğu c2 ve c3 meşcerelerinde ağaçlarda, Fe stoğu ise b2, b3, c2 ve c3 meşcerelerinde ölü örtüde en yüksek düzeydedir.

\section{Tartıșma}

Bu çalışmada, ağaç bileşenlerine ait besin yoğunlukları meşcere tiplerine göre önemli farklılıklar göstermiştir. İbrelerdeki N ve P yoğunluğu meşcere yaşına (meşcere gelişim çağına) bağlı olarak artarken; gövde odunundaki N, P ve K, kabuktaki P, $\mathrm{K}, \mathrm{S}$ ve Zn, kökteki Fe meşcere yaşına bağlı olarak azalış göstermiştir. Amerika'da Tectona grandis L. f. ağaçlandırmalarında yapılan çalışmada, farklı ağaç bileşenlerine ait $\mathrm{N}, \mathrm{P}, \mathrm{K}, \mathrm{Ca}, \mathrm{Mg}, \mathrm{S}, \mathrm{Fe}, \mathrm{Mn}$, $\mathrm{Cu}, \mathrm{Zn}$ ve $\mathrm{B}$ yoğunluklarının yaşa bağlı değişimi incelenmiştir (Fernandez-Moya ve ark., 2013). Bu çalışmaya göre, yapraklardaki Mg yoğunluğu meşcere yaşına bağlı olarak artarken; yapraklardaki N, daldaki $\mathrm{N}, \mathrm{K}, \mathrm{Mg}, \mathrm{Zn}$ ve $\mathrm{Cu}$, gövde odunundaki $\mathrm{N}$, $\mathrm{K}$ ve $\mathrm{Mg}$, kabuktaki $\mathrm{N}, \mathrm{K}, \mathrm{S}, \mathrm{Fe}$ ve $\mathrm{Mn}$ yoğunluğu meşcere yaşına bağlı olarak azalış göstermiştir.

Araştırmamızda ağaç bileşenlerine ait besin yoğunlukları meşcere yaşına bağlı olarak azalırken, ibrelerdeki $\mathrm{N}$ ve $\mathrm{P}$ yoğunluğu artmıştır. Türkiye ormanlarında yapılan araştırmaların derlendiği bir çalışmada, karaçam ibrelerindeki besin yoğunluklar1 $\mathrm{N} \%$ 0,75-2,34, $\mathrm{P} \%$ 0,02-0,26, K \% 0,14-1,55, $\mathrm{Ca} \% 0,09-0,95, \mathrm{~S} \% 0,09-0,13, \%$ Mg 0,06-0,31, Na 33-270 ppm, Fe 45,1-299,9 ppm, Mn 3,8-137,2 ppm olarak belirlenmiştir (Sevgi ve ark., 2001). İbrelerdeki besin yoğunluklarına ait bulgularımız Sevgi ve ark. (2001) tarafından yapılan çalışma ile uyum içerisindedir.

Besin elementi yoğunlukları bakımından ağaç bileşenleri arasında önemli farklılıklar bulunmuştur. $\mathrm{N}, \mathrm{P}, \mathrm{K}, \mathrm{Mg}, \mathrm{S}, \mathrm{Zn}$ ve Mn yoğunluğu ibrelerde, $\mathrm{Na}$ ve $\mathrm{Fe}$ yoğunluğu kuru dalda, $\mathrm{Ca}$ yoğunluğu ise kuru dal ve kabukta en yüksek düzeydedir. Farklı ağaç türleri üzerinde yapılan çalışmalarda da benzer bulgulara ulaşılmıştır (Hart ve ark., 2003; Balboa-Murıs ve ark., 2006; Armolaitis ve ark., 2013; Fernandez-Moya ve ark., 2013; Zhao ve ark., 2014; Novák ve ark., 2017). Araştırma bulgularımızdan farklı olarak, Pinus taeda türünde Ca en fazla ibrede (Zhao ve ark., 2014), Quercus robur türünde Fe en fazla yaprakta (Balboa-Murıas ve ark., 2006), Nothofagus türünde $\mathrm{P}$ ve $\mathrm{K}$ en fazla sürgünlerde (Hart ve ark., 2003) bulunmuştur. Bu durumun ağaç türleri arasındaki farklılıktan kaynaklandığ düşünülmektedir.
Karaçam ağaçlandırma alanlarında çalı olarak meşe, ardıç ve laden türleri bulunmaktadır. Bu türlerin toprak üstü kütlesine ait $\mathrm{N}, \mathrm{P}, \mathrm{K}, \mathrm{Ca}, \mathrm{Mg}, \mathrm{S}$, Fe ve $\mathrm{Zn}$ yoğunluğu ve toprak altı kütlesine ait $\mathrm{N}$, $\mathrm{P}, \mathrm{K}, \mathrm{Mn}, \mathrm{S}$ ve $\mathrm{Zn}$ yoğunluğu bakımından önemli farklılıklar belirlenmiştir. Besin yoğunlukları arasındaki bu farklılıklar, türler arasındaki farklılıktan kaynaklanmaktadır. Toprak üstü kütledeki N, P, K, $\mathrm{Mg}, \mathrm{S}$ ve $\mathrm{Zn}$ yoğunluğu laden türünde, Fe yoğunluğu ardıç ve laden türlerinde, Ca yoğunluğu ise meşe ve ardıç türlerinde en yüksek düzeydedir. Toprak altı kütledeki N, P, Zn ve Mn yoğunluğu laden türünde, $\mathrm{K}$ ve $\mathrm{S}$ yoğunluğu meşe ve laden türlerinde en yüksek düzeyde bulunmuştur.

Ölü örtüdeki N, P, S ve Fe yoğunluğu meşcere tipleri arasında önemli farklılık göstermiş ve a3 meşcerelerindeki besin yoğunluğu b ve c meşcerelerine göre daha düşük düzeyde bulunmuştur. Ölü örtüdeki besin yoğunluklarına ait bu bulgular, ibrelerdeki besin yoğunlukları ile benzerlik göstermektedir. Ölü örtüdeki N, P, S ve Fe yoğunluklarının meşcere yaşına bağlı olarak artmasının ibre dökümünden kaynaklandığı düşünülmektedir. Tecimen ve ark. (2001), karaçam ağaçlandırma alanları için ölü örtünün $\mathrm{N}, \mathrm{P}, \mathrm{K}, \mathrm{Ca}$ ve $\mathrm{Mg}$ yoğunluğunu sirasiyla \% $0,83,0,03,0,19,1,21$ ve 0,28 olarak belirlemişlerdir. Ölü örtüye ilişkin bulgularımız, Tecimen ve ark. (2001) tarafindan yapılan çalışma ile uyum içerisindedir.

Ağaç bileşenlerine ait besin stokları meşcere tipleri arasında önemli farklılıklar göstermiştir. Ağaç bileşenlerine ait besin stokları genel olarak a meşcerelerinden c meşcerelerine doğru artmış ve Çkc3 meşcerelerinde en yüksek düzeyde bulunmuştur. $\mathrm{Bu}$ durum, yaşın artmasına bağlı olarak kütlenin artmasından kaynaklanmıştır. Benzer şekilde, sarıçamda yapılan çalışmada yaşa bağlı olarak ağaçlardaki besin stoklarının arttığı ortaya konulmuştur (Novák ve ark., 2017).

Birim alandaki N, P, K, Ca, Mg, S, Na, Fe, Zn, $\mathrm{Mn}$ ve $\mathrm{Cu}$ stoğu ağaç bileşenleri arasında önemli farkl11ıklar göstermiştir. En fazla N, P, K ve S stoğu ibrede, $\mathrm{Mg}, \mathrm{Na}, \mathrm{Fe}, \mathrm{Zn}$ ve $\mathrm{Cu}$ stoğu gövdede, Ca stoğu gövde, canlı dal ve kabukta, Mn stoğu ise gövde ve ibrede bulunmuştur. Ağaçlarda depolanan makro besin elementlerinin ağaç bileşenlerine göre dağılımına bakıldığında en fazla ibre, gövde ve kabukta depolandığ 1 görülmektedir. Dolayısıyla, bakım ve gençleştirme çalışmalarından sonra ibre ve kabukların ormanda bırakılmasına azami özen gösterilmelidir. Keza, kızılçamda yapılan çalışmada, özellikle tensil çağındaki meşcerelerde kabuk biyokütlesinde yüksek miktarda Ca'un depolandığı bildirilmektedir (Eker ve ark., 2013). Yine sarıçamda yapılan bir çalışmada, ormanlarda 
kesim yapılması durumunda ağaçların dal, kabuk ve özellikle ibrelerinin ormanda bırakılmasının ormanın beslenmesi açısından son derece önemli olduğu belirtilmektedir (Tolunay, 2011). Ormana yapılan müdahaleler sonucunda ölü örtüye katılan artıklar, toprakta biriken besin elementlerinin ve besin döngüsünün temel kaynaklarından birini oluşturmaktadır. Bu sebeple, toprak verimliliğinin ve orman ekosisteminin ekolojik sürdürülebilirliğinin sağlanması bakımından ölü örtünün korunmasına önem verilmelidir (Güner ve Makineci, 2017). Yine, ölü örtünün bitki besin elementleri döngüsünün en önemli havuzu olduğu ve bu sebeple korunması gerektiği bildirilmektedir (Sarg1nc1, 2014).

Karaçam ağaçlandırma alanlarında ekosistemin farklı bileşenlerinde (ağaç, çalı, ot, ölü örtü ve toprak) depolanan besin stokları meşcere tipleri arasında önemli farklılıklar göstermiştir. Ağaçlardaki tüm besin stokları, meşcere kapalılığının ve gelişim çağının artmasına bağlı olarak artış göstermiş ve en fazla besin stoğu Çkc3 meşcerelerinde tespit edilmiştir. Bu durum beklenen bir olgudur. Çünkü besin stokları üzerinde, kütlenin etkisi, besin elementi yoğunluğundan daha fazla olmaktadır. Çalışmamızda, toplam ağaç kütlesi Çka meşcerelerinde 4,1 t/ha iken bu değer Çkc3 meşcerelerinde 212,5 t/ha'a ulaşmaktadır (Güner ve Çömez, 2014). Dolayısıyla kütle üzerindeki 52 katlık artış, besin stokları üzerinde de artışa sebep olmuştur. Konu ile ilgili olarak sarıçam'da yapılan bir çalışmada da benzer bulgulara ulaşılmış ve topraküstü biyokütlede depolanan besin stokları, yaşa bağlı olarak artış göstermiştir (Armolaitis ve ark., 2013).

Otlarda depolanan N, P, K, Mg, S, Na, Fe, Cu, Zn ve Mn stokları meşcere tipleri arasında önemli farklılıklar göstermiştir. Otlarda depolanan N, P, K, Mg, $\mathrm{S}, \mathrm{Na}, \mathrm{Fe}, \mathrm{Zn}, \mathrm{Mn}$ ve $\mathrm{Cu}$ stoğu Çka ve Çka3 meşcerelerinde en yüksek, Çkc3 meşcerelerinde ise en düşük düzeyde bulunmuştur. Çünkü Çka meşcerelerinden Çkc3 meşcerelerine doğru ağaç kütlesindeki artışa paralel olarak ot kütlesi azalış göstermiştir. Bu durum, 1şık yetersizliği sebebiyle kapalı meşcereler altındaki ot türlerinin daha az bulunmasından kaynaklanmıştır (Güner ve Çömez, 2014).

Ölü örtüde depolanan N, P, K, Ca, Mg, S, Na, Fe, $\mathrm{Zn}, \mathrm{Mn}$ ve $\mathrm{Cu}$ stoğu meşcere tipleri arasında önemli farklılıklar göstermiştir. Ölü örtüde depolanan besin stokları Çka meşcerelerinden Çkc3 meşcerelerine doğru artmıştır. Ölü örtü ile ilgili elde edilen bulgunun, canlı bitkisel kütle ile doğrudan ilişkili olduğu düşünülmektedir. Zira canlı bitkisel kütledeki artışa bağlı olarak ölü örtü kütlesinin, dolayısıyla besin stoklarının artması beklenen bir olgudur. Keza, Clark ve ark. (2001) tropikal orman- larda, toprak üstü ağaç kütlesi ile yıllık dökülme miktarı arasında pozitif ilişkilerin bulunduğunu bildirmektedir. Yine kızılçam ormanlarında, meşcere göğüs yüzeyi ile dökülme miktarı arasında önemli ilişkiler $\left(\mathrm{R}^{2}=0,7583\right)$ bulunmuştur (Erkan ve ark., 2018). Doğal sarıçam ormanlarında, meşcere göğüs yüzeyi ve bonitet endeksi ile dökülme miktarı arasında pozitif ilişkiler bulunmuş ve bu iki değişken dökülme miktarını \% 66,6 oranında açıklamıştır (Çömez ve ark., 2019).

Toprakta depolanan $\mathrm{Ca}$, Na ve Fe stoğu bakımından meşcere tipleri arasındaki farklılıklar önemli bulunurken $\mathrm{N}, \mathrm{P}, \mathrm{K}, \mathrm{Mg}, \mathrm{S}, \mathrm{Zn}, \mathrm{Mn}$ ve $\mathrm{Cu}$ stoğu bakımından ise önemsiz bulunmuştur. Toprakta depolanan $\mathrm{Ca}$, Na ve Fe stoğu Çka ve Çka3 meşcerelerinde en yüksek düzeydedir. Her ne kadar $\mathrm{Ca}$, $\mathrm{Na}$ ve Fe stoğu bakımından meşcere tipleri arasında önemli farklılıklar bulunmuş olsa da, bu farklılıkların meşcere tiplerinin etkisi altında oluştuğunu söylemek mümkün değildir. Çünkü bu çalışma, çok geniş bir coğrafya üzerinde yürütülmüş olup, topraklar farklı anakaya ve iklim özellikleri altında oluşmuş ve gelişmiştir. Örnek alanlardaki toprakları oluşturan anakayalar ile toprakların derinlik, taşlılık ve hacim ağırlığı özellikleri biribirlerinden oldukça farklılık göstermektedir.

Ekosistemde depolanan $\mathrm{P}, \mathrm{Ca}, \mathrm{S}, \mathrm{Na}$ ve Fe stoğu bakımından meşcere tipleri arasındaki farklılıklar önemli; N, K, Mg, Zn, Mn ve Cu stoğu bakımından ise önemsiz bulunmuştur. Ekosistemdeki P, S ve Fe stoğu Çkc3 meşcerelerinde, Ca ve Na stoğu ise Çka ve Çka3 meşcerelerinde en yüksek düzeydedir. Ekosistemde $\mathrm{S}$ ve $\mathrm{Fe}$ dışındaki besin stoklarının en önemli kısmını toprak oluşturmaktadır. Keza, Hart ve ark. (2003) tarafından Nothofagus türünde yapılan çalışmada, toprağın $60 \mathrm{~cm}$ derinliği için N, P, K, Mg ve Ca stoğu sirasiyla 2400, 439,5, 37200, 13000 ve $12800 \mathrm{~kg} / \mathrm{ha}$ olup, bu stokların ekosistemdeki toplam besin stoklarına oranı sirasıyla \% $72,62,98,99$ ve 88 olarak bulunmuştur. Kükürt stoğu c2 ve c3 meşcerelerinde ağaçlarda, Fe stoğu ise b2, b3, c2 ve c3 meşcerelerinde ölü örtüde en yüksek düzeydedir. Benzer şekilde, Quercus robur türünde yapılan çalışmada, ölü örtü Fe stoğu $(652,5$ $\mathrm{kg} / \mathrm{ha}$ ), ekosistemdeki demir stoğunun \% 56,6'sını oluşturmuştur (Balboa-Murıas ve ark., 2006). Dolayısıyla, ölü örtünün, ekosistemdeki demir stoğunun en önemli kısmını oluşturduğu söylenebilir.

\section{Sonuç ve Öneriler}

Karaçam ağaçlandırma alanlarında besin stoklarının belirlenmesi amacıyla gerçekleştirilen bu çalışmada aşağıdaki sonuçlara ulaşılmıştır: 
1. Ağaç bileşenlerine ait besin yoğunlukları meşcere tipleri arasında önemli farklılıklar göstermiştir. Genel olarak ağaç bileşenlerine ait besin yoğunlukları meşcere yaşına (meşcere gelişim çağına) bağlı olarak azalırken, ibrelerdeki N ve $\mathrm{P}$ yoğunluğu artış göstermiştir.

2. Besin elementi yoğunlukları ağaç bileşenleri arasında anlamlı faklılıklar göstermiş, N, P, K, $\mathrm{Mg}, \mathrm{S}, \mathrm{Zn}$ ve $\mathrm{Mn}$ yoğunluğu ibrelerde, $\mathrm{Na}$ ve Fe yoğunluğu kuru dalda, Ca yoğunluğu ise kuru dal ve kabukta en yüksek düzeyde bulunmuştur.

3. Ağaçlardaki tüm besin stokları, meşcere gelişim çağının ve kapalılığının artmasına bağlı olarak artış göstermiş ve en fazla besin stoğu Çkc3 meşcerelerinde tespit edilmiştir.

4. Ağaçlarda birim alandaki N, P, K ve $\mathrm{S}$ stoğu ibrede, $\mathrm{Mg}, \mathrm{Na}, \mathrm{Fe}, \mathrm{Zn}$ ve $\mathrm{Cu}$ stoğu gövdede, $\mathrm{Ca}$ stoğu gövde, canlı dal ve kabukta, Mn stoğu ise gövde ve ibrede en fazla bulunmuştur. Makro besin elementleri ağaçlarda en fazla ibre, gövde ve kabukta depolanmaktadır. Bu sebeple, bakım ve gençleştirme çalışmalarından sonra besin kaybını en az düzeye indirmek amaciyla ibre ve kabukların ormanda bırakılmasına azami özen gösterilmelidir. Özellikle dikili satış uygulamalarında, emvalin kabuklu olarak ormandan çıkartılmasına izin verilmemelidir.

5. Karaçam ağaçlandırma alanlarında, $\mathrm{S}$ ve $\mathrm{Fe}$ dışındaki besin stoklarının en önemli kısmını toprak oluşturmaktadır. Kükürt stoğu c meşcerelerinde ağaçlarda, Fe stoğu ise b ve c meşcerelerinde ölü örtüde en yüksek düzeyde bulunmuştur. Ölü örtü, gerek besin döngüsünün gerekse ekosistemdeki Fe stoğunun en önemli bileşenidir. $\mathrm{Bu}$ sebeple korunmasına önem verilmelidir.

6. Karaçam ağaçlandırmalarının biyoenerji olarak değerlendirilmesi düşünüldüğünde, meşcere tiplerine göre değişmekle birlikte, Çkc3 meşcerelerinde tüm ağaç hasadı yapılması durumunda, ekosistemdeki $\mathrm{N} \%$ 5,5, P \% 31,1, K $\%$ 20,8, Ca \% 2,7, Mg \% 3,0, S \% 38,6, Na \% 9,1, Fe \% 12,1, Zn \% 27,1, Mn \% 4,6 ve $\mathrm{Cu} \%$ 25,0 oranında azalacaktır. Eksilen besin maddesi stoklarının 2. ve 3. nesil ağaçlandırmaları ne yönde etkileyeceğinin araştırılması gerekmektedir.

\section{Teşekkür}

Bu çalışma, Prof. Dr. Kürşad ÖZKAN'ın danışmanlığında Süleyman Demirel Üniversitesi, Fen Bilimleri Enstitüsü, Orman Mühendisliği Anabilim Dalında hazırlanan yüksek lisans tezinin bir bölümü olup, Orman Genel Müdürlüğü, Orman Toprak ve Ekoloji Araştırmaları Enstitüsü Müdürlüğü tarafından "Karaçam ağaçlandırma alanlarında besin stoklarının belirlenmesi [ESK-28(6320)]" isimli proje kapsamında desteklenmiştir.

\section{Kaynaklar}

Armolaitis, K., Varnagiryte- Kabasinskiene, I., Stupak, I., Kukkola, M., Miksys, V., Wojcik, J., 2013. Carbon and nutrients of Scots pine stands on sandy soils in Lithuania in relation to bioenergy sustainability. Biomass and Bioenergy 54: 250-259. doi:10.1016/j.biombioe.2013.03.034

Balboa-Murias, M.A., Rojo, A., Álvarez, J.G., Merino. A., 2006. Carbon and nutrient stocks in mature Quercus robur L. stands in NW Spain. Annals of Forest Science 63: 557-565. doi:10.1051/forest:2006038

Clark, D.A., Brown, S., Kicklighter, D.W., Chambers, J.Q., Thomlinson, J.R., Ni, J., Holland, E.A. 2001. Net primary production in tropical forests: an evaluation and synthesis of existing field data. Ecol App. 11: 371384. doi:10.1890/1051-0761(2001)011[0371:NPPITF]2.0. $\mathrm{CO} ; 2$

Çepel, N., Dündar M., Özdemir T., Neyişçi, T., 1988. K1z1lçam (Pinus brutia Ten.) Ekosistemlerinde İğne Yaprak Dökümü ve Bu Yolla Toprağa Geri Verilen Besin Maddeleri Miktarları. İç Anadolu Ormancılık Araştırma Enstitüsü Müdürlüğü Yayınları, 20 s, Ankara.

Çömez, A., Tolunay, D., Güner, Ş.T., 2019. Litterfall and the effects of thinning and seed cutting on carbon input into the soil in Scots pine stands in Turkey. European Journal of Forest Research 138: 1-14. https://doi. org/10.1007/s10342-018-1148-6

Dündar, M., 1989. Bolu-Aladağ Mint1kasında Saf Sar1çam (Pinus sylvestris L.) Ormanlarının Beslenme-Büyüme İlişkileri. İstanbul Üniversitesi Orman Fakültesi Dergisi A39(1): 80-89.

EFC, 2010. Wood Energy For Europe: Status and Outlook. Europen Forestry Commission 35th Session, Lisbon, Portugal. EFC/2010/2.3 Available from, http://www.fao. org/docrep/meeting/018/k7431e.pdf; 27-30 April 2010 [Ziyaret Tarihi: 12.01.13]

Eker, M., Acar, H.H., Özçelik, R., Alkan, H., Gürlevik, N., Çoban, H.O., Korkmaz, M., Y1lmaztürk, A., 2013. Ormancılıkta Hasat Artıklarının Tedarik Edilebilirliğinin Araştırılması. TÜBİTAK-TOVAG $110 \mathrm{O} 435$ Numaralı Proje Sonuç Raporu, 435 s., Isparta.

Erkan, N., Comez, A., Aydin, A.C., Denli, O., Erkan, S., 2018. Litterfall in relation to stand parameters and climatic factors in Pinus brutia forests in Turkey. Scandinavian Journal of Forest Research 33(4): 338-346. doi: 10.1080/02827581.2017.1406135

Fernandez-Moya, J., Murillo, R., Portuguez, E., Fallas, 
J.L., Rios, V., Kotmann, F., Verjans, J.M., Mata, R., Alvarado, A., 2013. Nutrient concentration age dynamics of teak (Tectona grandis L.f.) plantations in Central America. Forest Systems 22(1): 123-133. doi:10.5424/ fs/2013221-03386

Foss Tecator 2014. Numune Hazırlama/yakma işlemi. Application Note.

Güner, Ş.T., 2006. Türkmen Dağ1 (Eskişehir, Kütahya) Sarıçam (Pinus sylvestris ssp. hamata) Ormanlarının Yükseltiye Bağlı Büyüme Beslenme İlişkilerinin Belirlenmesi. Anadolu Üniversitesi, Fen Bilimleri Enstitüsü, Doktora Tezi, 298s, Eskişehir.

Güner, Ş.T., Çömez, A., 2014. Karaçam (Pinus nigra Arn. subsp. pallasiana) Ağaçlandırma Alanlarında Karbon Stoklarının Belirlenmesi. Orman Genel Müdürlüğü, Orman Toprak ve Ekoloji Araştırmaları Enstitüsü Müdürlüğü, Proje Sonuç Raporu: ESK-10(6303), 46s, Eskişehir.

Güner, S.T., Makineci, E., 2017. Determination of annual organic carbon sequestration in soil and forest floor of Scots pine forests on The Türkmen Mountain (Eskişehir, Kütahya). Journal of the Faculty of Forestry Istanbul University 67(2): 109-115. doi:10.17099/jffiu.199494

Hart, P.B.S., Clinton, P.W., Allen, R.B., Nordmeyer A.H., Evans, G., 2003. Biomass and Macro-Nutrients (above-andbelow-ground) in a New Zealand Beech (Nothofagus) Forest Ecosystems: Implications For Carbon Storage And Sustainable Forest Management. Forest Ecology and Management 174: 281-294. doi:10.1016/ S0378-1127(02)00039-7

Irmak, A., Çepel, N.,1969. Artım ve Beslenme ile Yapraklardaki Besin Maddesi Muhtevası Arasındaki İlişkileri Tespit Gayesi İle Bazı Karaçam Meşcerelerinde Yapılan Araştırmalar. İstanbul Üniversitesi Orman Fakültesi Dergisi A19(1): 1-28.

IUSS Working Group WRB, 2015. World reference base for soil resources 2014, update 2015. International soil classification system for naming soils and creating legends for soil maps. World Soil Resources Reports No. 106. FAO, Rome.

Kacar, B., 1994. Toprak Analizleri. Ankara Üniversitesi, Ziraat Fakültesi, Eğitim, Araştırma ve Geliştirme Vakfı Yayınları, 705s, Ankara.

Kacar, B., İnal, A., 2008. Bitki Analizleri. Nobel Yayın Dağıtım, Nobel Yayınları, 892s, Ankara.

Kairiūkštis, L., Jaskelevičius B., 2003. Forest Energy Resources and Their Utilization in Lithuania. Baltic Forestry 9(2): 29-41.

Kandemir, A., Matarac1, T., 2018. Pinus L. Editörler: Güner, A., Kandemir, A., Menemen, Y., Yıldırım, H., Aslan, S., Ekşi, G., Güner, I., Çimen, A. Ö. Resimli Türkiye Florası 2: 324-354. ANG Vakfı Nezahat Gökyiğit
Botanik Bahçesi Yayınları. İstanbul.

Kantarc1, M.D., 1979. Aladağ Kütlesinin (Bolu) Kuzey Aklanındaki Uludağ Göknarı Ormanlarında Yükselti-İklim Kuşaklarına Göre Bazı Ölü Örtü ve Toprak Özelliklerinin Analitik Olarak Araştırılması. İstanbul Üniversitesi Orman Fakültesi Yayınları, 220 s, İstanbul.

Kantarc1, M.D., 1980. Aladağ Kütlesinin (Bolu) Kuzey Yamacında Uludağ Göknarı İbrelerindeki Mineral Madde Miktarının Yükselti-İklim Kuşaklarına Göre Değişimi. Ístanbul Üniversitesi Orman Fakültesi Dergisi A30(2): 135-145.

Kantarc1, M. D., 2005. Orman Ekosistemleri Bilgisi, İstanbul Üniversitesi Orman Fakültesi Yayınları, 379s, İstanbul.

Major, J.E., Johnsen, K.H., Barsi, D.C., Campbell, M., 2012. Fine and coarse root parameters from mature black spruce displaying genetic $\mathrm{x}$ soil moisture interaction in growth. Can. J. For. Res. 42: 1926-1938. doi:10.1139/ x2012-144

Novák, J., Dušek, D., Kacálek, D., Slodıčák, M., 2017. Analysis of biomass in young Scots pine stands as a basis for sustainable forest management in Czech lowlands. Journal of Forest Science 63(12): 555-561. doi: 10.17221/136/2017-JFS

OGM, 2015. Türkiye Orman Varlığı 2015. T.C. Orman ve Su İşleri Bakanlığı, Orman Genel Müdürlügüü, 32s., Ankara.

Özyuvac1, N., 1999. Meteoroloji ve Klimatoloji, İstanbul Üniversitesi Orman Fakültesi Yayınları, 369s, İstanbul.

Pamir, H.N., Erentöz, C., 1975. 1/500.000 Ölçekli Türkiye Jeoloji Haritası Ankara Paftası, Maden Tetkik ve Arama Enstitüsü Yayınları, Ankara.

Ranger, J., Gelhaye, D., 2001. Bellowground biomass and nutrient content in a 47-year-old Douglas-fir plantation. Annals of Forest Science 58: 423-430.

Saatçioğlu, F., 1969. Silvikültür I, Silvikültürün Biyolojik Esasları ve Prensipleri. İstanbul Üniversitesi Orman Fakültesi Yayınları, 323s, İstanbul.

Sargınc1, M., 2014. Bat1 Karadeniz Orman Ekosistemlerinde Ölü Örtü Dinamiği. Düzce Üniversitesi, Fen Bilimleri Enstitüsü, Doktora Tezi, 157s, Düzce.

Sevgi, O., Makineci, E., Tecimen, H.B., 2001. An Investigation of the Nutrient Amounts of Main Conifer Forests in Turkey. Proceedings of the Fifth International Conference on the Development of Wood Science Wood Technology and Forestry, ICWSF 2001, Ljubljana, Slovenia, 175-184.

SPSS v.22.0®, 2015. SPSS 22.0 Guide to Data Analysis, published by Prentice Hall, Upper Saddle River, New Jersey, USA. 
Tecimen, H.B., Sevgi, O., Makineci, E., 2001. Investigations on Physicial and Chemical properties of Forest Floor in Turkey. Proceedings of the Fifty International Conference on the Development of Wood Science Wood Technology and Forestry, ICWSF 2001, Ljubljana, Slovenia, 185-195.

Tolunay, D., 2003. Aladağ'da (Bolu) sıklık çağındaki sarıçam (Pinus sylvestris L.) meşcerelerinde bakımların madde dolaşımına etkileri. Ístanbul Üniversitesi Orman Fakültesi Dergisi A53(1): 47-73.

Tolunay, D., 2011. Genç sarıçam ormanlarında canlı ağaçların topraküstü kısımlarındaki karbon ve besin maddesi stokları. Ekoloji 2011 Sempozyumu, Bildiri Özetleri s 81, 5-7 May1s 2011, Düzce.
TSE 8338, 1990a. Topraklar-Fosfor Tayini (Modifiye Bray ve Kurtz No. 1 Metodu). TSE, I. Bask1, Ankara.

TSE 8340, 1990b. Topraklar-Fosfor Tayini (Olsen ve Ark. Metodu). TSE, I. Bask1, Ankara.

TSE 8341, 1990c. Topraklar-Potasyum Tayini. TSE, I. Bask1, Ankara.

Zhao, D., Kane, M., Teskey, R., Markewitz, D., Greene, D., Borders, B., 2014. Impact of Management on Nutrients, Carbon and Energy in Aboveground Biomass Components of Mid-Rotation Loblolly Pine (Pinus taeda L.) Plantations. Annals of Forest Science 71: 843-851. doi:10.1007/s13595-014-0384-2 